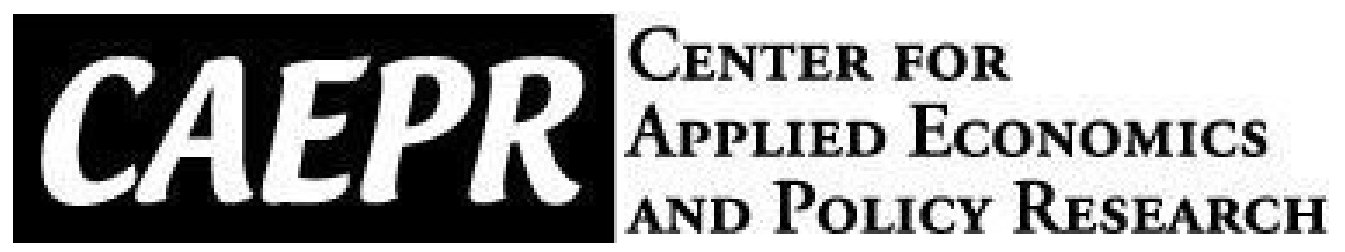

\author{
CAEPR \\ Working Paper \\ \#2018-004
}

\title{
The Effects of Official and Unofficial Information on Tax Compliance
}

\author{
Filomena Garcia \\ Indiana University, \\ \& UECE \\ Luca David \\ Opromolla Banco \\ de Portugal, CEPR, \\ CESifo, \& UECE
Andrea Vezzulli
University of
Insubria \\ Rafael Marques \\ ISEG-School of \\ Economics and \\ Management
}

March 2018

This paper can be downloaded without charge from the Social Science Research Network electronic library at https://papers.ssrn.com/abstract_id=3166305

The Center for Applied Economics and Policy Research resides in the Department of Economics at Indiana University Bloomington. CAEPR can be found on the Internet at: http://www.indiana.edu/ -caepr. CAEPR can be reached via email at caepr@indiana.edu or via phone at 812-855-4050.

(C)2018 by Filomena Garcia, Luca David Opromolla, Andrea Vezzulli and Rafael Marques. All rights reserved. Short sections of text, not to exceed two paragraphs, may be quoted without explicit permission provided that full credit, including (C) notice, is given to the source. 


\title{
The effects of official and unofficial information on tax compliance*
}

\author{
Filomena Garcia \\ Luca David Opromolla \\ Indiana University, \& UECE \\ Banco de Portugal, CEPR, CESifo, \& UECE \\ Andrea Vezzulli \\ University of Insubria \\ Rafael Marques \\ ISEG-School of Economics and Management
}

This version: March 2018

\begin{abstract}
The administration of tax policy has shifted its focus from enforcement to complementary instruments aimed at creating a social norm of tax compliance. In this paper we provide an analysis of the effects of the dissemination of information regarding the past degree of tax evasion at the social level on the current individual tax compliance behavior. We build an experiment where, for given levels of audit probabilities, fines and tax rates, subjects have to declare their income after receiving either a communication of the official average tax evasion rate or a private message from a group of randomly matched peers about their tax behavior. We use the experimental data to estimate a dynamic econometric model of tax evasion. The econometric model extends the Allingham-Sandmo-Yitzhaki tax evasion model to include self-consistency and endogenous social interactions among taxpayers. We find four main results. First, tax compliance is very persistent. Second, the higher the official past tax evasion rate the higher the degree of persistence: evaders are more likely to evade again, and compliant individuals are more likely to comply again. Third, when all peers communicate to have evaded (complied) in the past, both evaders and compliant individuals are more likely to evade (comply). Fourth, while both treatments, and especially the unofficial information treatment, are associated, in the context of our experiment, with a significantly larger growth in evasion intensity, the aggregate effect depends on the characteristics of the population. In countries with inherently low levels of tax evasion, official information can have beneficial effects by consolidating the behavior of compliant individuals. However, in countries with inherently high levels of tax evasion, official information can have detrimental effects by intensifying the behavior of evaders. In both cases, the impact of official information is magnified in the presence of strong peer effects.
\end{abstract}

Keywords: Tax morale, Information, Tax evasion, Experiment, Peer Effects

JEL Classification:H26; D63; C24; C92; Z13

\footnotetext{
*Acknowledgements : We thank Debrah Meloso and Brigitte Ferreira for helping with the experimental design and implementation. The paper benefited from discussions with Pedro dal Bó, Penelope Hernandez, James Walker and Daniela Puzzello, as well as the Experimental Economics group at Indiana University, and the participants of the PET Meetings in Taipei. The team gratefully acknowledges financial support from UECE-FCT. This article is part of the Strategic Project (UID/ECO/00436/2013). Luca David Opromolla thanks the hospitality of the Department of Economics at the University of Maryland, and at Indiana University, where part of this research was conducted. The analysis, opinions, and findings represent the views of the authors, they are not necessarily those of Banco de Portugal. Correspondence by e-mail: figarcia@indiana.edu, luca.opromolla@nyu.edu, andrea.vezzulli@uninsubria.it, rmarques@iseg.utl.pt
} 


\section{Introduction}

"[...] there is an apparent disconnect between much of the academic literature on tax compliance and the administration of tax policy. While tax administrators are obviously concerned about enforcement, they also tend to place a great deal of emphasis on improving "tax morale," by which they generally mean increasing voluntary compliance with tax laws and creating a social norm of compliance."

- Luttmer and Singhal (2014)

The above quote from Luttmer and Singhal (2014), emphasizing the disconnect between the academic literature and the concerns of tax administrators, is the underlying motivation of this study. Traditional economic models of tax evasion assume that individuals maximize their expected utility, considering that there is a certain probability of audit and fines for non-compliant behavior (Allingham and Sandmo, 1972 ; Yitzhaki, 1974). The key policy parameters are the tax rate, the audit and detection probabilities, and the fines conditional on the evasion being detected. However, these traditional models do not account for social interaction or, in the terminology of Moscovici (1961) and Moscovici and Duveen (2000), 'social representations' as determinants of tax compliance. Social representations include social norms, tax morale and a sense of civic duty, at a societal level, and subjective knowledge and perceptions of taxes, fairness and income distribution, at an individual level. If 'social representations' are a driver of individual tax compliance, tax authorities can then resort - in a complementary fashion - to instruments other than the tax and audit rate, and fines to promote "voluntary compliance" (OECD, 2001).

In this paper, we extend the existing literature on tax evasion to disentangle the effects of information on the past tax behavior of a reference group on the current individual tax behavior. We run an experiment allowing for two different sources of information that we call "official" and "unofficial". Official information is provided to the agents by the "tax authority", while unofficial information is the result of voluntary individual communication between peers. Both types of information studied in this paper are increasingly available to taxpayers around the world: the U.S. Internal Revenue Service (IRS) regularly reports information on the average voluntary compliance rate - defined as the ratio between total taxes paid and total taxes owed - as well as the gross tax gap - defined as the amount of true tax liability that is not paid voluntarily and timely (Matthews, 2017; Internal Revenue Service, 2016, 2012, 2006). People are also aware of the tax compliance behavior of their peers: the 2014 Tax Statistical Yearbook of Sweden reports that the share of people that personally know other people that evaded taxes is between 16 and 31 percent, while the share of businesses that personally know businesses that evaded taxes is between 9 and $29 \% 1$

Understanding the effects of information on tax behavior is key to support policies that encourage voluntary compliance. These types of policies are particularly appealing, both to tax administrators and academics, because they can have a multiplier effect. Consider an intervention aimed at praising tax compliance or deprecating widespread tax evasion in a specific region of country or in a specific occupational category. If the intervention is effective and individual tax compliance increases in the targeted region or occupational group then there can be positive spillovers effects on other regions or occupational groups

\footnotetext{
${ }^{1}$ Authors's calculations for the 2001-2006 period plus 2012 using Swedish Tax Agency data (Swedish Tax Agency (2014)).
} 
that are connected - e.g. through work, family, friendship ties. In other words, a shock to individual compliance can be amplified through social influences. Examples of actual interventions that go in this direction include television and print advertising campaigns in Italy and "name and shame" programs in several U.S. states and European countries aimed at changing the social attitude towards evasion by hinging on the feelings of guilt and shame for failure to comply (Povoledo, 2011).

This paper relies on the data produced by an experiment designed according to the standard features of income tax systems. In order to provide guidance to the analysis of the experimental data, we extend the standard Allingham-Sandmo-Yitzhaki tax evasion model (Allingham and Sandmo, 1972, Yitzhaki, 1974) by introducing self-consistency and endogenous social interactions among taxpayers. We then specify an econometric model, that is consistent with our theory, to identify the effect of different types of information on individual tax behavior.

The experiment involved subjects recruited from the pool of undergraduate and graduate students from a major public university in Portugal. The subjects, participating in computer sessions with repeated rounds, had to report their income to a tax authority. Each subject's income was randomly allocated and agents were informed of the tax schedule, the probability of audit and the fines. We considered two treatments and one control. In treatment $A$, the subjects were informed of the average percentage of income not reported by all the participants (i.e. "the economy") in the previous round. In Treatment B, subjects were randomly matched in groups of four, and they were allowed to communicate about their tax behavior in the previous round to their three partners. The control group received no information, neither official nor non-official, on past tax evasion rates. We then specify an econometric model, consistent with a theoretical tax evasion model a lá Allingham-Sandmo-Yitzhaki (Allingham and Sandmo, 1972 , Yitzhaki, 1974) extended to consider self-consistency and endogenous social interactions among taxpayers, to identify the effect of different types of information on individual tax behavior. We pay particular attention - following the seminal Manski (1993) paper - to the challenges posed by the identification of social effects. First, we control for correlated effects and sorting biases by randomizing participants across groups, as in Fortin et al. (2007), and we randomize the location of each participant in the experimental computer lab to limit the possibility that informal chats between participants may affect results. Second, we control for individual random effects to capture all the time-invariant individual-specific observed and unobserved characteristics of the participants, like risk-aversion or intrinsic motivations. Third, we estimate a dynamic model where the participant's evasion behavior in $t-1$ and/or in $t-2$ can affect her behavior in $t$.

Estimates of the econometric model can be summarized in four main results. First, we provide robust evidence for the presence of a strong state persistence in tax compliance. A subject who complied at time $t-1$ has an estimated average probability of about 0.85 to keep complying at time $t$ if she also complied in $t-2$. This predicted probability reduces to 0.52 if the subject instead evaded at time $t-2$.

Second, we find that official information on past tax behavior may exacerbate differences in the individual tax behavior of "evaders" and "compliant individuals" (henceforth, "compliants"): the greater the average evasion intensity (in $t-1$ ) officially communicated, the larger is the probability to evade in $t$ for those subjects who had already evaded in $t-1$. The estimated average magnitude of this effect is between 2.1 and 3.5 percentage points for a one percentage point increase in the communicated average evasion intensity. Conversely, the greater the average evasion intensity (in $t-1$ ) officially communicated 
the smaller is the probability to evade in $t$ for those subjects who had complied in $t-1$. The estimated average magnitude of this effect is about -3.0 percent for a one percentage point increase in the average evasion intensity. This result is reminiscent of Dwenger et al. (2016), who consider a treatment in which those paying at least the required amount of the local Protestant church tax have a probability of having their names published in a local newspaper, should they wish to. The authors find that this treatment reduces payments for those who had evaded the church tax in the past, while it increases payments for all others, indicating that intrinsic motivation is an important factor in tax compliance.

Third, we find that unofficial information pointing to low tax compliance- unlike official information - can reverse the behavior of individuals. Subjects who received the unofficial information that all their peers had evaded in $t-1$ are more likely to evade ( $+29 \%$ in estimated probability of evasion), independently of their past tax behavior. The effect is actually stronger for those subjects that had complied in $t-1(+40 \%)$ than for those that had evaded in $t-1(+15 \%)$. On the contrary, we find no statistically significant effect when all the peers communicated that they had complied.

Fourth, in the context of our experiment, both treatments, and especially the unofficial information treatment, are associated with a significantly larger growth in evasion intensity. Over the course of the experiment, the growth in evasion intensity associated to the official and unofficial treatments is, on average, about 65 percent and 25 percent higher, respectively, than that of the control group, which is fairly flat. Part of this differential is due to the extensive margin, i.e. to the larger growth in the share of evaders. While both treatments are associated, in the context of our experiment, with a significantly larger growth in evasion intensity, the aggregate effect depends on the characteristics of the population. In countries with inherently low levels of tax evasion, official information can have beneficial effects by consolidating the behavior of compliants. However, in countries with inherently high levels of tax evasion, official information can have detrimental effects by intensifying the behavior of evaders. In both cases, the impact of official information is magnified in the presence of strong peer effects.

On top of these main results, we also find evidence of the so-called "bomb-crater" effect-i.e. the drop in tax compliance following an audit - and offer an important qualification of this result:2 the likelihood of evading right after having being audited is stronger for taxpayers who had actually complied than for taxpayers who had evaded (and were caught cheating). We actually find that the effect disappears for the latter group. Finally, we confirm that subjects whose income is slightly above the tax rate threshold, are more likely to evade (Saez, 2010 and Bastani and Selin, 2014). We also show that in our data the tax rate threshold effect is stronger for taxpayers that are male, and that had complied in the previous period.

We now briefly discuss the connection of this study to the literature. The articles most closely related to ours are those by Fortin et al. (2007) and Alm et al. (2009). Like Fortin et al. (2007) we are interested in studying the effects that information on the tax compliance of others has on a subject's own tax behavior. Fortin et al. (2007) consider an experiment where participants all receive the same endowment and must decide how much income to report given their tax rate and audit probability, given those faced by the other members of their group, and given the group's mean reported income. Their results provide evidence of fairness effects but reject social conformity both in the case of myopic expectations and in the

\footnotetext{
${ }^{2}$ This effect was first documented experimentally by Guala and Mittone $(2005)$ and Mittone (2006), and formalized in a social network model of tax compliance by Hashimzade et al. (2014).
} 
case of self-consistent expectation (whenever simultaneity issues are controlled for). Besides a number of differences in the experimental design, our main departure with respect to Fortin et al. (2007) is in considering two different sources of information regarding the tax behavior of others: the mean reported evasion intensity vs. the communication of evasion intensity from "peers". Unlike Fortin et al. (2007), we find robust evidence of social conformity effects at work.

Our study is also complementary to Alm et al. (2009), whose focus is to identify the effects on compliance of different means by which the tax authority can inform the taxpayers about the actual degree of audit frequency. As in Alm et al. (2009) we distinguish between "official" and "unofficial" sources of information but, unlike in their paper, we do not consider any source of uncertainty regarding the tax authority enforcement effort. We instead focus on information regarding the tax compliance behavior of the population or of the subject's peers, conditional on the time-invariant and exogenous enforcement effort of the tax authority.

Besides the papers cited above, our paper is related to a number of strands in the literature. The previous economic literature has considered the possibility that individual tax decisions are affected by social norms and social interactions (see, for instance, Andreoni et al. 1998). Aspects such as the preference for social conformity, and the effects of reference points have been included in the theoretical literature that aims to explain the determinants of compliance/evasion (e.g. Gordon, 1989 and Myles and Naylor, 1996). The experimental literature, however, is still not definitive. In an important survey paper, Luttmer and Singhal (2014) conclude: "We view this body of evidence as indicative of a role for peer effects and social influences in tax compliance but much remains to be learned about the circumstances under which interventions targeting these motivations are effective in changing behavior".

Other authors have investigated the psychological effects of information on tax behavior. Baldry (1986) tried to verify the discouraging effects produced when tax declarations are made public and when the experimental design takes the form of a real world situation. Baldry's main results are that when tax declarations are kept private, evasion increases, while it decreases when tax declarations are public. In our study we show that the effects of the dissemination of information regarding tax compliance at the social level depend both on the source (official vs. peers) and the target group (evaders vs. compliants).

Within the literature on tax behavior, our paper focuses on dynamic decision making: the information that the subjects receive in the experiment concerns the previous period behavior of the participants. In this specific context we aim at studying the persistence of compliance or evasion as agents receive new information. Our paper is one of the few to focus on the issue of persistence in tax behavior. Alm and Yunus (2009) find empirically strong evidence of persistence and strategic interaction among individuals in their tax evasion behavior. Regarding persistence, the authors' estimation points towards both shortand long-run effects of audit rates on compliance. In our paper we also find evidence of persistence in tax behavior and on the reaction to the different types of information. Our paper also relates to Mittone (2006) who studies experimentally the effects of a repetitive dynamic choice process on subjects' attitude towards risk. Mittone (2006) focuses mostly on the tax yield redistribution as psychological factor influencing tax behavior. Other papers study the dynamic effects of tax behavior. For instance, Soliman et al. (2014) explore experimentally the dynamic interaction between audit and penalty rates as individuals learn how to comply with taxation. In our paper, we focus mostly on the effects of peers' actions and information on individual risk preference. 
The rest of the paper is organized as follows. The next section introduces a dynamic model of tax evasion with information and peer effects, and discusses a number of theories consistent with the mechanisms included in the theoretical model. Section 3 presents the experimental design, and discusses its external validity. In Section 4, after defining some key variables, we show raw data evidence on persistence in tax compliance, and on the effect of information regarding past tax behavior of other subjects. Section 5 presents the econometric model, and discusses identification issues. All the results from the raw data evidence are confirmed by the econometric testing of Section 6, which includes our baseline estimates as well as a number of robustness tests. In this section we also show that, besides affecting individual decisions, the provision of information has substantial aggregate effects. Finally, Section 7 concludes, followed by three appendices that provide theoretical proofs, variable definitions, additional descriptive statistics, and more details regarding the experiment.

\section{A model of tax evasion with information and peer effects}

In this section we introduce self-consistency and endogenous social interactions among taxpayers into the standard Allingham-Sandmo-Yitzhaki tax evasion model (Allingham and Sandmo, 1972 and Yitzhaki, 1974).

\subsection{Basic setup}

There is a set of individuals denoted by $\mathcal{N}$. Each period $t$, a taxpayer $i \in \mathcal{N}$ receives a random income (or endowment) from a Uniform distribution, $I_{i t} \sim U[\underline{I}, \bar{I}]$, and must decide how much of that income to declare, $\left.D_{i t}\right]^{3}$ The tax rate according to the declared income is denoted by $\tau(D)$. For simplicity, we assume here that the tax rate is constant and equal to $\tau$, whereas in the experimental setup we allow for a progressive tax rate. The probability of audit is given by $p$. If the taxpayer $i$ is found guilty of evading taxes she must pay the evaded taxes, $\tau\left(I_{i t}-D_{i t}\right)$, plus a commensurate penalty $\theta \tau\left(I_{i t}-D_{i t}\right)$ with $\theta \geq 0$. If the individual is not audited, her net income is $\bar{I}_{i t}=I_{i t}-\tau D_{i t}$. If she is audited, the net income is $\underline{I}_{i t}=I_{i t}-\tau D_{i}-(\theta+1) \tau\left(I_{i t}-D_{i t}\right) 4^{4}$ The decision of the agent is repeated for $t=1, \ldots T$ periods. Let $F_{i t}=D_{i t} / I_{i t} \in[0,1]$ denote the share of reported income. We label a subject that chooses $F=1$ as "compliant" and $F \in[0,1)$ as "evader".

\subsection{Modeling the tax evasion decision}

We assume, as in Fortin et al. (2007), that the taxpayer does not derive any utility from the public goods that the tax may eventually finance. Subject $i$ 's expected utility, $E U_{i}$, is then assumed to consist of four separable components:

$$
\begin{gathered}
E U_{i}=\left[p u\left(\bar{I}_{i t}\right)+(1-p) u\left(\underline{I}_{i t}\right)\right] \\
+\gamma_{1} s\left(F_{i t}, F_{i t-1}\right)+\gamma_{2} g\left(F_{i t}, F_{i t-1}, \Omega_{t-1}\right)+\lambda_{i} \mathcal{I}\left(F_{i t}=1\right),
\end{gathered}
$$

\footnotetext{
${ }^{3}$ The random income has been introduced so that income effects are not dominating in the tax behavior.

${ }^{4}$ Of course, the two constraints coincide in the case of full compliance, i.e. $D_{i t}=I_{i t}$.
} 
where the first two terms of equation (1) represent the private expected utility associated with tax compliance behavior. We assume that $u(\cdot)$ is increasing and concave in income, which implies that the individual is risk-averse. The first term on the second line of equation (1) represents individual temporal consistency, or lack thereof, in tax behavior, and depends on both the contemporaneous and lagged tax evasion decision. The third component represents social conformity and depends on the information, $\Omega_{t-1}$, that the subject receives about the last period reporting decisions of a subset of the population. The last component, where $\mathcal{I}($.$) is an indicator function, captures the individual's intrinsic motivation (i.e.$ $\lambda_{i}>0$ ) —or lack thereof (i.e. $\lambda_{i}<0$ ) — to pay all taxes. Finally, $\gamma_{1}, \gamma_{2}$ are positive scaling parameters.

If $\gamma_{1}, \gamma_{2}$, and $\lambda_{i}$ are all zero, then we return to the traditional static model with no self-consistency, social conformity effects, and intrinsic motivations. If $\gamma_{1}>0$, the function $s\left(F_{i t}, F_{i t-1}\right)$ encompasses both temporal self-consistency and self-inconsistency, depending on the supermodularity or submodularity of $s(\cdot)$ with respect to $\left(F_{i t}, F_{t-1}\right)$. If $s(\cdot)$ is supermodular the share of income currently reported by the taxpayer, $F_{i t}$, should be, ceteris paribus, increasing in the share of income reported in the previous period, $F_{i t-1}$. If $s(\cdot)$ is submodular the opposite applies $5^{5}$ In the empirical analysis, this component of the utility function can potentially capture persistence in the tax behavior of subjects over time. As we show in the empirical analysis, the degree of persistence in tax behavior is generally high, especially for compliants 6

If $\gamma_{2}>0$, the function $g\left(F_{i t}, F_{i t-1} ; \Omega_{t-1}\right)$ represents the component of the individual preferences that depends on the information regarding the behavior of other agents in the previous period. It encompasses both social conformity and anti-conformity. Assuming that higher values of $\Omega$ are associated with more widespread underreporting and given that lower values of $F$ are associated with higher individual underreporting, submodularity of $g(\cdot)$ implies that preferences exhibit strategic complementarities as in Brock and Durlauf (2001) 7 The presence of $F_{i t-1}$ as an argument allows the submodularity or supermodularity of $g(\cdot)$ with respect to $\left(F_{i t}, \Omega_{t-1}\right)$ to depend on the behavior of the agent in $t-1$. An equivalent way to interpret the effect of $\Omega$ is to think that the information received regarding the behavior of other agents may strengthen or weaken the degree of self-consistency captured by $s(\cdot)$.

Finally, if $\lambda_{i}>0$ subject $i$ has an intrinsic motivation for paying taxes: independently from subject $i$ 's behavior in $t-1$ and from the information received regarding the behavior of other agents, subject $i$ 's expected utility is higher if she reports her income in full than if she underreports it. Conversely, if $\lambda_{i}<0$ individual $i$ has an intrinsic motivation for not paying taxes in full, which could be associated with a community-wide propensity to evade, to the individual perception of unfairness of the tax system, or to negative reciprocity motives linked to a poor relationship with the state and its policies.

From the model specified above we can test several hypothesis concerning the strength of the selfconsistency effect and of the conformity effect with past tax behavior. For instance, an individual that has complied in the past and obtains information of high compliance will have, under self consistency and strategic complementarities, aligned incentives to comply in the current period. However, if the information received is of low compliance by a (sub)set of the population, then, his actions depend on

\footnotetext{
${ }^{5}$ By assuming smoothness of $s(\cdot)$, a simple test for supermodularity (submodularity) of the function is whether $\partial^{2} s(\cdot) / \partial F_{i t} \partial F_{i t-1} \geq 0(\leq 0)$ (see Amir, 2005).

${ }^{6}$ In the econometric model of Section 5 , we allow for a more complex dependence by considering the relationship between $F_{i t}$ and both $F_{i t-1}$ and $F_{i t-2}$. The Akaike Information Criterion (AIC) and Bayesian Information Criterion (BIC) tests show that the two-lags model is the preferred one in the data.

${ }^{7}$ We assume that $g(\cdot)$, just like $s(\cdot)$, is concave, and that subject $i$ 's effect on $\Omega$ is negligible.
} 
how the information received affects the degree of self-consistency: if social conformity is weak then the subject will comply again, while if social confirmity is strong, and dominates the self-consistency effect, then the subject may switch his behavior and evade.

Assuming that preferences satisfy the Von Neuman-Morgenstern axioms, the individual's problem is to choose the share of reported income, $F_{i t}$, so as to maximize her expected utility (1) subject to the inequality conditions $0 \leq F_{i t} \leq 1$. Instead of assuming specific functional forms to find the optimal share of reported income we present a formulation that is in line with the econometric model that we estimate in Section 5. Let us first solve the optimization problem ignoring the inequality constraints on the optimal share of reported income. The equation for $F_{i t}^{*}$, the latent variable associated with $F_{i t}$, can be written as:

$$
F_{i t}^{*}=F^{*}\left(Z_{i t}, F_{i t-1}, \Omega_{t-1}\right) \text {, }
$$

where $Z_{i t}$ is a set of subject-time controls. The relationship between the observed variable $F_{i t}$ and the latent variable $F_{i t}^{*}$ is:

$$
F_{i t}=\mathcal{I}\left(0 \leq F_{i t}^{*}<1\right) F_{i t}^{*}+\mathcal{I}\left(F_{i t}^{*} \geq 1\right) .
$$

From this model we can derive the following predictions regarding tax evasion:

Proposition 1 (Underreporting) A risk-averse individual will always underreport her income (i.e. $\left.F_{i t}<1\right)$ whenever

$$
1-(1+\theta) p-\gamma_{1} \frac{s_{1}\left(1, F_{i t-1}\right)}{u_{1}\left(I_{i t}\right) I_{i t} \tau}-\gamma_{2} \frac{g_{1}\left(1, F_{i t-1}, \Omega_{t-1}\right)}{u_{1}\left(I_{i t}\right) I_{i t} \tau}>0,
$$

where $u_{1}=\partial u(\cdot) / \partial I_{i t}, s_{1}(\cdot)=\partial s(\cdot) / \partial F_{i t}$ and $g_{1}(\cdot)=\partial g(.) / \partial F_{i t}$.

Proof. See Appendix A.1.

Proposition 1 shows that a risk-averse individual prefers to evade taxes when the expected return from that action, $1-(1+\theta) p$, adjusted to take into account the marginal private consistency cost of tax evasion, $\gamma_{1} s_{1}\left(1, F_{i t-1}\right) / u_{1}\left(I_{i t}\right) I_{i t} \tau$, and the marginal social cost of tax evasion, $\gamma_{2} g_{1}\left(1, F_{i t-1}, \Omega_{t-1}\right) / u_{1}\left(I_{i t}\right) I_{i t} \tau$, is strictly positive.

Proposition 2 (Persistence) If $s(\cdot)$ and $g(\cdot)$ are supermodular in $\left(F_{i t}, F_{t-1}\right)$, then a risk-averse individual is more likely to underreport (i.e. $F_{i t}<1$ ) if she had underreported in $t-1$ (i.e. if $F_{i t-1}<1$ ) than if she had complied in $t-1$ (i.e. if $F_{i t-1}=1$ ).

Proof. See Appendix A.2.

Proposition 2 implies that if $s(\cdot)$ and $g(\cdot)$ are supermodular in $\left(F_{i t}, F_{t-1}\right)$ then we expect to observe persistence in tax evasion. In this case persistence originates from self-consistency.

Proposition 3 (Effect of Information on persistence) If the degree of supermodularity of $g($.$) in$ $\left(F_{i t}, F_{t-1}\right)$ is increasing in $\Omega_{t-1}$, i.e if $\partial g_{12}(\cdot) / \partial \Omega_{t-1}>0$, then a risk-averse individual is more likely to underreport in $t$ if she had underreported in $t-1$ (to comply in $t$ if she had complied in $t-1$ ) upon receiving information of higher evasion by a subset of the population. On the contrary, if the degree of supermodularity of $g($.$) is decreasing in \Omega_{t-1}$, i.e if $\partial g_{12}(\cdot) / \partial \Omega_{t-1}<0$, then a risk-averse individual is more likely to underreport in $t$ if she had complied in $t-1$ (to comply in $t$ if she had underreported in $t-1)$ upon receiving information of higher evasion by a subset of the population. 
Figure 1: Persistence and information on the extent of evasion

(a) Persistence increasing with the extent of evasion

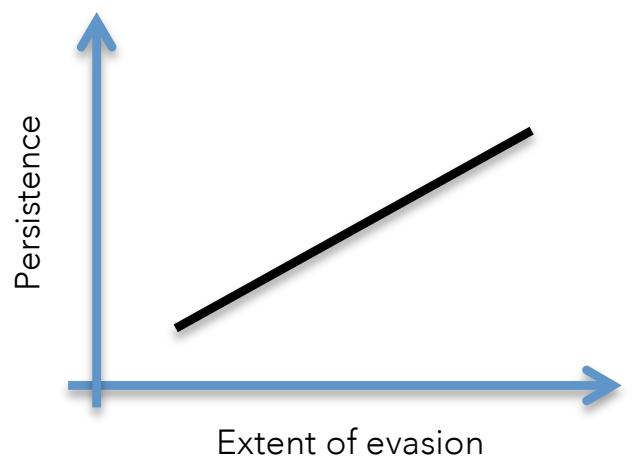

(b) Persistence decreasing with the extent of evasion

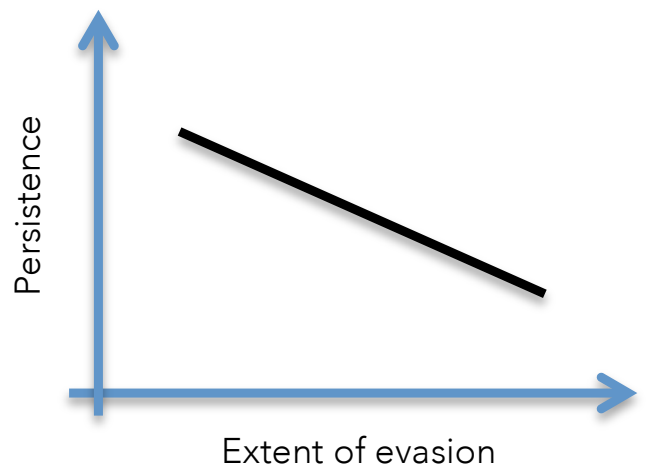

\section{Proof. See Appendix A.3.}

Proposition 3 implies that information on the behavior of a set of the population affects the persistence of individual behavior. Figure 1 depicts the two cases considered in Proposition 3 ; information of higher widespread evasion leads to higher persistence when the intertemporal strategic complementarities increase with information of high evasion, i.e. $\partial g_{12}(\cdot) / \partial \Omega_{t-1}>0$, in (Panel a), and to less persistence otherwise, i.e. $\partial g_{12}(\cdot) / \partial \Omega_{t-1}<0$, in (Panel b).

As we will see in the analysis of the experimental data, the effect of official and unofficial information on persistence is not the same. We find that official information on the extent of evasion increases persistence for all subjects: when receiving information of widespread evasion subjects who had evaded in $t-1$ are more likely to evade in $t$ as well; likewise, subjects who had complied in $t-1$ are also more likely to comply in $t$. In terms of the theory, the effect of official information is consistent with all subjects behaving according to Panel a of Figure 1. The effect of unofficial information transmitted via group communication is different. We find that subjects that are informed that all their peers had evaded in $t-1$ are generally more likely to evade in $t$. Likewise, subjects that are informed that all their peers had complied in $t-1$ are generally more likely to comply in $t$. In terms of the theory, the effect of unofficial information is consistent with agents that had evaded in $t-1$ behaving (in $t$ ) according to Panel a of Figure 1, and agents that had complied in $t-1$ behaving (in $t$ ) according to Panel $\mathrm{b}$ of Figure 1 .

\subsection{Discussion}

A number of theories that have been discussed in the literature are consistent with the fact that the information received regarding the tax compliance of other agents may affect a subject's own tax compliance. In this section we discuss some of these theories in the light of the theoretical model proposed in the previous section, as they will facilitate the interpretation of the econometric results shown later on.

Feelings of guilt or shame. Cheating on taxes may cause feelings of guilt or shame (Brian Erard, 1994, Andreoni et al., 1998; Luttmer and Singhal, 2014). As such, a subject that declared less than her actual income in $t-1$ may be more likely to keep evading, or evade more, in $t$ if she knows that evasion is pervasive among the other subjects. In other words, the decision to evade affects how society views 
a taxpayer or how the taxpayer views herself; it is social interaction because the effect depends on the behavior of others $8^{8}$ Information about a high (as opposed to low) degree of tax evasion by others can increase the likelihood of evasion by subjects that had already evaded in the previous period, through a reduction in the feelings of guilt or shame. On the contrary, it's possible that a subject who had complied in $t-1$ may be more likely to comply again in $t$ if she knows that evasion is pervasive among the other subjects. Information on widespread evasion may reinforce in this case the feelings of pride of a subject who had complied in $t-1$. As a consequence, this subject may be more likely to keep complying.

Of course, the extent of social conformity or social anti-conformity may not be constant and may depend on how high is the degree of tax evasion. A subject that had complied in $t-1$ may be more likely to comply again upon receiving information of a positive but small tax evasion rate. This is the case, mentioned above, in which the subject experiences feeling of pride in complying with the tax policy. However, the same subject may "forget her own pride", and start evading upon receiving information of a high official tax evasion rate, or upon knowing that most of her peers did evade. In other words, when analyzing the impact of information on tax compliance it might be important to consider the "distance" between a subject's behavior and the behavior of the group about which the information is conveyed.

Group identification. Independently from feelings of guilt or shame, when taxpayers identify with the group of subjects they receive information about they might internalize their social norms and act concurrently $9^{9}$ It is then possible that upon receiving strong information about the widespread degree of tax evasion of a group of peers, a subject may be more likely to evade taxes in $t$, indipendently from her behavior in $t-1$. Likewise, upon receiving strong information about the low degree of tax evasion of a group of peers, a subject may be less likely to evade taxes in $t$, indipendently from her behavior in $t-1$.

Endogenous audit and uncertainty. Subjects may reduce their tax evasion whenever they receive information on higher tax evasion by the other subjects, out of fear this may trigger a higher audit rate. This effect might be particularly strong for subjects who had not been audited recently, as they may feel a likely target of the (expected) more intense auditing policy. Alternatively, subjects may be uncertain about the probability of an audit, or about the penalty rate. The information received about the behavior of other subjects may affect this uncertainty. Snow and Warren (2005) show that an increase in uncertainty would drive ambiguity averse taxpayers to comply more and ambiguity lovers to comply less 10

\section{Experimental Design}

In this section we describe in detail the experiment that is the source of the data used in our econometric analysis. Further information about the experiment, as well as the complete set of instructions distributed to the participants can be found in Appendix C.

\footnotetext{
${ }^{8}$ See Bénabou and Tirole (2011) for a model of social norms, and Besley et al. (2015) for a dynamic extension.

${ }^{9}$ Wenzel (2004) emphasizes the role of social identification as a process transforming a social group into a self-category and reference group whose norms are internalized and acted upon as one's own personal views.

${ }^{10}$ While theoretically appealing, both these latter explanations are less likely to apply to our experiment since, as described in Section 3. we made it clear that the audit rate and the penalty rate were constant across rounds and subjects.
} 
The experiment has been designed according to the features of the voluntary income reporting and tax assessment system used in many countries. Human participants in a controlled computerized laboratory environment are attributed randomly a certain level of income (or endowment), and - after receiving some, or no information about the behavior of others - decide how much of this income to report to a tax agency. Taxes are paid on reported income only. Agents are subject to random audits where unreported income may be discovered. In that case, the participant must pay the owed taxes plus a fine proportional to the amount of unpaid taxes. At the completion of the experiment, all participants are paid in cash their laboratory market earnings converted to Euro. The policy question investigated is: "how does the compliance behavior of individuals change upon the release of different types of information?" The experimental design addresses this question by introducing treatments that provide different information regarding the tax behavior of other agents. Our experimental design follows the elements of much of the earlier experimental research on tax behavior, namely Alm et al. (1992a), Alm et al. (2009) and Becker et al. (1987).

Participants are recruited from the pool of undergraduate and master students at a major public university in Portugal. The participants are randomly assigned to either the control or the treatment group, and will play in separate sessions. Table C.1 provides a summary of the main steps involved in the control and treatment sessions with the number of participants and rounds per session 11 Upon arrival at the laboratory, each subject is randomly assigned to a computer station. Instructions are provided via hard copy and read out loud. The final earnings of the participants depend on their income, reporting behavior, and audit experience. The total income earned by each subject at the end of the session is the sum of the net income earned at the end of each round. The payment of the subjects was done in euros according to the following exchange rate: 4,000 experimental euros=1 Euro. A participation premium of 5 Euro was paid to cover participation expenses ${ }^{12}$

Control groups The individuals assigned to the control group participated to 3 practice rounds followed by 12 real rounds. After the practice rounds are completed, any final procedural question is answered. The number of rounds is fixed and known by the participants at the beginning of each session. In each control session, the subjects receive information about their income (or endowment), $I$, a random value uniformly distributed between 500 and 4,500 laboratory euros. Subjects do not know the realized distribution of incomes in their group, they just know that incomes are independently and identically extracted from a uniform distribution. Subjects declare their income for the purpose of taxation. After that, each subject is informed of her net income, after taxes and after possible fines are charged. That

\footnotetext{
${ }^{11}$ Overall we have 74 participants (1,704 observations), of which 16 participants (384 observations) belong to the control group and 58 participants (1,320 observations) to the treatment group. There are 6 sessions for each treatment (official and unofficial information), and 4 control sessions. Therefore the observations related to the control are 384-16 participants playing 4 sessions of 12 periods each. Each participant assigned to the treatment group played treatments comprising 12 rounds. All participants (except six, who just played the official treatment sessions) played both types of treatments. Therefore the observations related to the treatment are $1,320-52$ participants playing 12 rounds for each treatment, plus 6 participants playing 12 rounds of the official treatment.

${ }^{12}$ Participants had the option, in case of negative earnings, of either continuing the experiment but giving up the participation premium or terminating the experiment and receive just the participation premium. In practice, all participants completed the experiment. In the econometric analysis, we control both for the current and cumulated earnings of the subject.
} 
finalizes the round 13 All the subjects participating in each session of the control group know ex-ante the probability of being audited $(p=0.25)$, the fine rate $(\theta=6)$, the total number of rounds $(T=12)$, and the tax rate according to the scheme reported in Table C.2.

Treatment groups The individuals assigned to the treatment group participated in two different treatments, labelled A (official information) and B (peer communication). Each treatment comprises 3 practice rounds - just meant for the subjects to get used to the software and the experiment rules - followed by 12 real rounds. After the practice rounds are completed, any final procedural question is answered. The order in which each group of subjects plays the treatments - $3+12$ rounds of Treatment A followed by $3+12$ rounds of Treatment B or vice versa - is random in each session. The number of rounds is fixed and known by the participants at the beginning of each session.

Following the same initial protocol for the control group, at the beginning of each round the agents receive the information about their income, $I$, a random value uniformly distributed between 500 and 4,500 laboratory euros. Subjects do not know the realized distribution of incomes in their group, they just know that incomes are independently and identically extracted from a uniform distribution. Then, in all rounds except the first one, the subjects receive information regarding the reporting behavior of other agents in the preceding round. Here the information received is different between treatment A and treatment B. In treatment $\mathrm{A}$, the subjects are informed about the official average unreported income among all the session subjects in the previous round. The number of participants in each session for treatment $\mathrm{A}$ is either 8,10 or 1214 In treatment $\mathrm{B}$, the subjects are randomly matched in groups of four participants. These groups are maintained throughout all rounds of the session. The participants do not know who is in their group, they only know the number of peers in their group. Participants are not allowed to communicate with one another during the session except when allowed via the computer interface. In each round (except the first), the agents are asked whether they want to send a message - the same message - to the other three members of their group. The message regards the percentage of income reported in the previous period, chosen from a grid going from 0 to 1 with steps of 0.1 . Then, each player receives a message from the other three players who wish to communicate ${ }^{15}$ Finally, in both treatments, the subjects declare their income for taxation purposes. The round finishes when the individuals receive information of their net income, after taxes and after possible fines are charged. All the subjects know ex-ante the probability of being audited $(p=0.25)$, the fine rate $(\theta=6)$, the total number of rounds $(T=12)$ and the tax rate according to the scheme reported in Table C.2 ${ }^{16}$

\footnotetext{
${ }^{13}$ In half of the control group sessions, subjects are informed about their net income and fines only at the end of the session. We do not exploit, in the econometric analysis, this difference and focus on comparing treatment groups, where either official or unofficial information is active, to control groups.

${ }^{14}$ In the econometrics analysis we control for the heterogeneity in the number of participants.

${ }^{15} \mathrm{As}$ in Alm et al. (2016), we find that, in most of the cases (87.5\% of the cases in our experiment), individuals were accurate whenever they sent messages about their own compliance behavior to their peers. In the remaining $12.5 \%$ of the cases individuals were dishonest (or inaccurate) in the content of their "unofficial" communication. Nevertheless, differently from Alm et al. (2016), the aim of our paper is not to check the accuracy of the information communicated "per-se", but to assess the effect of this communication on the behavior of other taxpayers.

${ }^{16}$ The use of experimental data helps avoiding endogeneity biases and measurement errors that can potentially affect studies that use audit or survey data. In our experiment the probability of being audited is exogenous. Studies that use audit or survey data have to control for the fact that the probability of auditing is generally related to the extent of underreporting.
} 


\subsection{External validity}

Our experiment has been designed according to the features of the voluntary income reporting and tax assessment system used in many countries. It is, nonetheless, a simplified version of real-life situations. We discuss here a number of caveat affecting the external validity of the experiment.

Information, and representativeness. A possible issue for the external validity of the experiment is that participants may be more informed than in real-life. We believe that this is not necessarily the case, and probably it will be less and less so in the future: as mentioned above, tax agencies frequently report a number of statistics that are informative of the average level of tax compliance: for example, the U.S. Internal Revenue Service (IRS) regularly reports information on the average voluntary compliance rate - defined as the ratio between total taxes paid and total taxes owed - as well as the gross tax gap - defined as the amount of true tax liability that is not paid voluntarily and timely (Matthews, 2017; Internal Revenue Service, 2016, 2012, 2006). People are also aware of the tax compliance behavior of their peers: The 2014 Tax Statistical Yearbook of Sweden reports that the share of people that personally know other people that evaded taxes - in the 2001-2006 period plus 2012 - is between 16 and 31 percent. The share of businesses that personally know businesses that evaded taxes is between 9 and 29\% (Swedish Tax Agency (2014)).

Another aspect of tax compliance experiments that is often discussed in the literature is if the pool of subjects, tipically undergraduate students, is representative of the behavior of the general population. In our experiment, the pool of subjects consists of students, as in most of the literature. However, a substantial percentage of students are over 24 years old and they are not unemployed (between 20 and 38 percent, for both traits, see Table B.1), which means that the pool of subjects shows a reasonable balance in terms of experience in participating to the labor force and the tax system.

Reference groups. In real-life the reference group against which to measure the presence of social conformity effects - e.g. family, closests friends, colleagues - is partly endogenous. In the part of the experiment related to the "unofficial" information treatment we randomly assign participants to groups of four. This allows us to side-step a number of counfounding issues - e.g. matching biases - and to achieve a much cleaner identification of endogenous interactions. Even if the group is exogenously formed, the fact that our participants are students of similar age and employment status, and enrolled in the same university is consistent with a core characteristic of the real-life network structure of social interactions emphasized by the literature on social networks: "homophily", i.e. the tendency of various types of individuals to associate with others who are similar to themselves (Currarini et al. (2009)).

Contextual framework, fairness and reciprocity. We have purposedly decided to contextualize the experiment talking explicitly, in the experiment instructions, about "declared income", "audit", "unpaid taxes"...(see Appendix C), and mentioning that the aim of the study was to study the determinants of fiscal evasion. To the best of our knowledxge, in the literature there is not a dominant choice between adopting a neutral terminology or talking explicitly about taxes and tax evasion. Alm et al. (1992b) run the same experiment in both contexts and find identical results. Baldry (1986) emphasizes the importance of an experimental design that takes the form of a real world situation: subjects' behavior changes if they are asked to take decisions in a context which resembles a gambling game as opposed to a real world situation.

Unobserved heterogeneity. Even though we do not mention explicitly the use of the tax revenue, we 
Table 1: Evasion propensity and intensity, and other descriptive statistics, by type of session

\begin{tabular}{|c|c|c|c|c|c|c|}
\hline \multirow[t]{2}{*}{ Variable } & \multicolumn{2}{|c|}{ Control } & \multicolumn{2}{|c|}{$\begin{array}{c}\text { Treatment A } \\
\text { (Official) }\end{array}$} & \multicolumn{2}{|c|}{$\begin{array}{c}\text { Treatment B } \\
\text { (Unofficial) }\end{array}$} \\
\hline & Mean & (Std. dev.) & Mean & (Std. dev.) & Mean & (Std. dev.) \\
\hline Evade $(0 / 1)$ & 0.281 & $(0.450)$ & 0.455 & $(0.498)$ & 0.462 & $(0.499)$ \\
\hline Unreported income (\%) & 5.689 & $(13.875)$ & 13.276 & $(22.305)$ & 15.602 & $(25.331)$ \\
\hline Aver. evasion intensity in t-1 (\%) & & & 13.179 & $(5.933)$ & & \\
\hline All evaded in $t-1(0 / 1)$ & & & & & 0.050 & $(0.217)$ \\
\hline All complied in t-1 $(0 / 1)$ & & & & & 0.045 & $(0.207)$ \\
\hline \multicolumn{7}{|l|}{ No. periods of evasion (\%) } \\
\hline 0 & & 28.12 & & 17.24 & & 19.23 \\
\hline $1-3$ & & 40.63 & & 20.69 & & 11.55 \\
\hline $4-6$ & & 12.50 & & 22.41 & & 21.16 \\
\hline $7-9$ & & 9.36 & & 27.59 & & 32.69 \\
\hline $10-12$ & & 9.36 & & 12.06 & & 15.39 \\
\hline Observations & & 384 & & 638 & & 624 \\
\hline
\end{tabular}

Notes: The top panel of this table shows the average and standard deviation for the main variables and samples considered in the empirical analysis of Section 5 by type of session. Table B.1 reports summary statistics for all variables considered in the analysis. The definition of all variables can be found in Appendix B The bottom panel of the table reports, by type of session, the distribution of the number of periods of evasion.

believe that, sharing a similar background, all the participants have in mind the Portuguese tax and public expenditure system. The tax compliance behavior of the participants is then likely affected by their own perception of the fairness of the tax system, and by their own individual relationship with the state. Since we use individual random effects in the econometric analysis we believe we are controlling for most of this unobserved heterogeneity.

\section{Key definitions, and evidence from raw data}

In this section we present a set of descriptive statistics on the persistence of tax compliance, and on the relationship between persistence and the type of information received. These results are consistent with the model that we outlined in the theoretical section, and will be confirmed by the more sophisticated multivariate analysis of Section 6 .

We focus on two indicators of tax non-compliance: evasion propensity and evasion intensity. Evasion propensity is defined as the share of subjects who underreports their income. The subject's choice to evade is codified as a dummy variable equal to one if the subject declares less than her income, and zero otherwise ${ }^{17}$ Evasion intensity is defined as the share of unreported income. Table 1 (top panel) presents summary statistics on a selection of variables of interest in the three samples (control, treatment A, and

\footnotetext{
${ }^{17}$ In order to take into account potential rounding and unintentional income mis-reporting errors we codified the dummy variable to be equal to one only when the percentage of unreported income is greater than 1 percent. Similarly, evasion intensity is recoded to zero when the percentage of unreported income is lower than 1 percent.
} 
Table 2: Persistence in evasion: Transition matrices

(a) All sessions

\begin{tabular}{|c|c|c|}
\hline & Complied in $\mathrm{t}$ & Evaded in $\mathrm{t}$ \\
\hline Complied in t-1 & 0.717 & 0.283 \\
\hline Evaded in t-1 & 0.383 & 0.617 \\
\hline
\end{tabular}

(c) Treatment A

\begin{tabular}{|c|c|c|}
\hline & Complied in t & Evaded in t \\
\hline Complied in t-1 & 0.691 & 0.309 \\
\hline Evaded in t-1 & 0.368 & 0.632 \\
\hline
\end{tabular}

(b) Control sessions

\begin{tabular}{|c|c|c|}
\hline & Complied in t & Evaded in t \\
\hline Complied in t-1 & 0.791 & 0.209 \\
\hline Evaded in t-1 & 0.559 & 0.441 \\
\hline
\end{tabular}

(d) Treatment B

\begin{tabular}{|c|c|c|}
\hline & Complied in t & Evaded in t \\
\hline Complied in t-1 & 0.656 & 0.344 \\
\hline Evaded in t-1 & 0.390 & 0.610 \\
\hline
\end{tabular}

Notes: The table reports the one-period transition matrix in evasion propensity for the whole sample, as well as separately for the control, treatment A, and treatment B sessions samples.

treatment B).

\subsection{Persistence in tax compliance and evasion}

Compliance is a persistent decision. The bottom panel of Table 1 shows the distribution of the number of periods of evasion, and indicates that there is significant persistence in the observed tax compliance decision of the participants in the experiment. For example, to take an extreme case, if individual outcomes (evasion vs. compliance) were independent draws from a binomial distribution with fixed probability equal to 0.28 (the average evasion propensity in the control sample), then about 2 percent of the sample would be expected to always comply. In contrast, the sample relative frequency is about 28 percent.

Compliance is also more persistent than evasion. Table 2 reports the one-period transition matrix between evasion and compliance for the whole sample as well as for each type of session. As expected, there is generally more persistence in the compliance status than in the evasion status: in the whole sample, the probability of complying in $t$ given compliance in $t-1$ is about 72 percent, while the probability of evasion in $t$ given evasion in $t-1$ is about 62 percent.

\subsection{How information affects persistence in tax compliance and evasion}

We now anticipate the main set of results that we will establish in the empirical analysis of Section 5 .

Information on the behavior of others affects both the evasion propensity and intensity. Information on the income reporting behavior of other participants affects the propensity to evade, as well as the evasion intensity. The first two rows of Table 1 report the average evasion propensity and average evasion intensity for the three types of sessions: treatment A (official information), treatment B (unofficial information), and control. We observe that the type of external information provided to the participants of treatment $\mathrm{A}$ and $\mathrm{B}$ affects both their evasion propensity and evasion intensity, which are, on average, larger than those of the participants in the control session (who didn't receive any kind of external information).

While it is clear that information affects the income reporting behavior, we also find that the effect of official and unofficial information is different, and that information affects differently subjects who had evaded or not in the past. 
Figure 2: Probability to comply/evade, and share of reported/unreported income as a function of the officially communicated average evasion intensity (Treatment A - Official information)
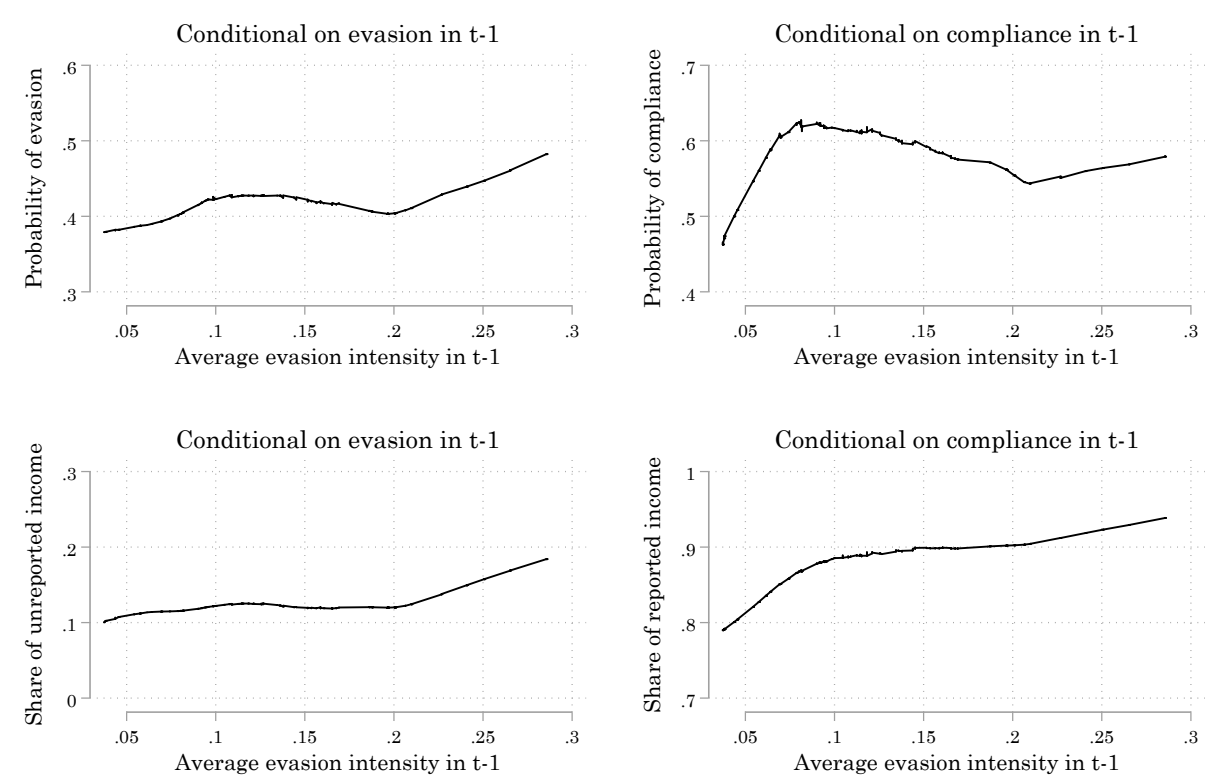

\begin{abstract}
Notes: The figure shows the smoothed trendlines of the average compliance or evasion propensity (top) and share of reported/unreported income (bottom) as a function of the $t-1$ average evasion intensity officially communicated. The plots on the left side refer to subjects who had evaded in the previous period. The plots on the right side refer to subjects who had complied in the previous period. Evasion propensity and intensity are defined in Section 4 and Appendix B
\end{abstract}

The higher the (communicated) official average evasion intensity, the higher is the persistence in tax behavior for all subjects. Figure 2 shows the average compliance/evasion propensity (top panels) and compliance/evasion intensity (bottom panels) in $t$ as a function of the official average evasion intensity in $t-1$. The left panels regard subjects who had evaded in $t-1$, while the right panels regard subjects who had complied in $t-1$. We observe that the higher is the communicated average evasion intensity in $t-1$ the higher is the probability to evade and the higher is the share of unreported income, for subjects that had evaded in $t-1$ (left panels). Moreover, the higher is the communicated average evasion intensity in $t-1$ the higher is the probability to comply and the higher is the share of reported income, for subjects that had complied in $t-1$ (right panels). This latter effect is particularly relevant for low levels of communicated evasion intensity, consistently with the theory, discussed above, that subjects who comply may experience feeling of pride in doing so, as long as the "others" do not evade too much. Overall, we observe an upward trend in persistence, as a function of the "officially" communicated average evasion intensity, both for compliants and evaders. This behavior that we observe in the data is broadly consistent with the theoretical prediction of Panel a of Figure 1 .

Information that all your peers evaded (complied) makes it more likely for you to evade (comply), irrespective of your past behavior. Table 3 reports the average evasion or compliance propensity in $t$, as 
Table 3: Probability to comply/evade, and share of reported/unreported income as a function of peer communicated evasion intensity (Treatment B - Unofficial information)

\begin{tabular}{|c|c|c|c|c|}
\hline & \multicolumn{2}{|c|}{ Evaders in t-1 } & \multicolumn{2}{|c|}{ Compliants in t-1 } \\
\hline & $\begin{array}{l}\text { Probability of } \\
\text { evasion in } t\end{array}$ & $\begin{array}{c}\text { Share of unreported } \\
\text { income in } t\end{array}$ & $\begin{array}{l}\text { Probability of } \\
\text { compliance in } t\end{array}$ & $\begin{array}{l}\text { Share of reported } \\
\text { income in } t\end{array}$ \\
\hline $\begin{array}{l}\text { (A) Upon receiving the information } \\
\text { that all peers evaded in } t-1\end{array}$ & 0.818 & 0.406 & 0.222 & 0.784 \\
\hline (B) Otherwise & 0.591 & 0.212 & 0.669 & 0.908 \\
\hline Difference (A) - (B) & $0.227^{* *}$ & $0.194^{* * *}$ & $-0.447^{* * *}$ & $-0.123^{* *}$ \\
\hline $\begin{array}{l}\text { (C) Upon receiving the information } \\
\text { that all peers complied in } t-1\end{array}$ & 0.400 & 0.202 & 0.652 & 0.912 \\
\hline (D) Otherwise & 0.614 & 0.229 & 0.656 & 0.903 \\
\hline Difference (C) - (D) & -0.214 & -0.027 & 0.004 & -0.008 \\
\hline Observations & 264 & 264 & 308 & 308 \\
\hline
\end{tabular}

Notes: The table reports the average evasion or compliance propensity and the share of unreported or reported income of subsets of participants according to the type of information received by three other randomly assigned subjects (peers). The difference in evasion/compliance propensity or intensity between subejcts that received a communication and the others is statistically significant at the $1 \%(* * *), 5 \%(* *), 10 \%(*)$ level.

well as the average share of reported or unreported income, as a function of the information that subjects received from their peers. We consider two types of information that a subject might receive: "all peers evaded in the previous period" or "all peers complied in the previous period". The left panels regard subjects who had evaded in $t-1$, while the right panels regard subjects who had complied in $t-1$. We observe that subjects that receive the information that all their peers had evaded in the previous period are more likely to evade themselves in the current period, independently from their behavior in the last period (top panel of Table 3). We also find that these subjects tend to underreport their income even more. A simple mean equality t-test shows that the difference in evasion propensity or intensity between subjects who receive this kind of "strong" information and those who do not is significant at 1 or 5 percent. By comparing the difference in the probability of evasion between evaders and compliants, we find that the "social conformity" effect seems to be particularly strong for those subjects who are "the furthest away" from the communicated behavior, i.e. those subjects who had complied in $t-1$.

We then consider the case of subjects receiving the information that all their peers had complied in the previous period (bottom panel of Table 3), and find that this information tend to reduce the evasion propensity and intensity of those subjects that had evaded in the previous period, even though the difference in the unconditional averages is not statistically significant. Again, by comparing the difference in the probability of compliance between evaders and compliants, we find that the effect of 
"social conformity" seems to be particularly strong for those subjects who are "the furthest away" from the communicated behavior, i.e. those subjects who had evaded in $t-1$.

Overall, we find that communication from peers can significantly alter the reporting behavior: subjects who had complied in $t-1$ might evade in $t$ upon knowing that all peers had evaded; similarly, subjects who had evaded in $t-1$ might comply in $t$ upon knowing that all peers had complied. This behavior is consistent with subjects that had evaded in $t-1$ behaving (in $t$ ) according to Panel a of Figure 1 . and agents that had complied in $t-1$ behaving (in $t$ ) according to Panel b of Figure 1. In other words, information from peers might increase the persistence in tax behavior for some subjects, and instead push other subjects to change their behavior.

All the findings regarding how official and unofficial information affect the income reporting behavior will be confirmed in the multivariate empirical analysis of the next section.

\section{$5 \quad$ Econometric model}

We now specify an econometric model that is consistent with the theory outlined in Section 2 . First we describe the model, then we discuss a number of important identification issues, and then we bring the model to the data in order to analyze if and how the type of information received affects the persistence of the subjects' evasion decisions. As we showed in Section 4 , there is a strong tendency for persistence in tax compliance which clearly requires the use of a dynamic model. We therefore resort to dynamic generalized equations models (Heckman, 1981, Hyslop, 1999) to disentangle the serial persistence in tax non-compliance behavior into: (i) true state dependence, which occurs when the action taken by a given individual $i$ at time $t-1\left(y_{i t-1}\right)$, has a genuine effect on the decision taken by the same individual at time $t\left(y_{i t}\right)$; and (ii) spurious state dependence, which occurs when the correlation between $y_{i t-1}$ and $y_{i t}$ is driven by the presence of time-invariant unobserved individual-effects $\eta_{i}$, i.e.

$$
D\left(y_{i t} \mid y_{i t-1}, \eta_{i}\right)=D\left(y_{i t} \mid \eta_{i}\right)
$$

Let $y_{i t}^{*}$ be the latent desired level of unreported income. We then expect to observe evasion when $y_{i t}^{*}>0$ and compliance when $y_{i t}^{*}=0$. We model the decision to evade or not by subject $i$ at time $t$ with a Dynamic Correlated Random Effect Probit model (Hyslop, 1999, Wooldridge, 2005, Stewart, 2006) 18 The empirical specification for modeling intertemporal tax evasion decisions involves the following dynamic reduced form specification for equation $(2), 19$

$$
\begin{gathered}
y_{i t}^{*}=\gamma y_{i t-1}+\mathbf{x}_{\mathbf{i t}}^{\prime} \boldsymbol{\beta}+\alpha_{i}+u_{i t} \\
y_{i t}=1\left[y_{i t}^{*}>0\right]
\end{gathered}
$$

where $\mathbf{x}_{i t}$ is a vector of observed demographic and economic variables, as well as characteristics of the experimental design that may affect the tax evasion decision; $\alpha_{i}$ is an individual-specific time-invariant term that captures, for example, heterogeneity across individuals in the intrinsic motivation for paying

\footnotetext{
${ }^{18}$ In subsection 6.1.1, we discuss advantages and disadvantages of this estimation approach and check the robustness of our results using linear probability models in a difference-in-difference setting.

${ }^{19}$ In the empirical analysis we allow for two lags of the dependent variable. The Akaike Information Criterion (AIC) and Bayesian Information Criterion (BIC) tests show that the two-lags model is the preferred one.
} 
taxes, i.e. the last component of equation $(1) ; u_{i t} \sim N\left(0, \sigma_{u}^{2}\right)$ captures the effects of unobserved (timevarying) factors; and $(\gamma, \boldsymbol{\beta})$ are a set of parameters. Specifically, $\mathbf{x}_{i t}$ contains: subject $i$ 's gross income (before taxes and fines) received at time $t$; subject $i$ 's net income (after taxes and fines) earned at the end of round $t-1$; subject $i$ 's total net income, at the beginning of round $t$, cumulated from the beginning of the session 20 a dummy variable equal to one when the current gross income of subject $i$ is 100 euros above the threshold of the assigned tax rate; a dummy variable equal to one when subject $i$ was audited in $t-1$ and zero otherwise; a similar dummy for being audited in $t-2$; the number of periods since the beginning of the session; a dummy variable equal to one if the subject is unemployed; a dummy variable equal to one if the subject is more than 24 years old; a dummy variable equal to one if the subject is male.

We adopt the methods proposed by Mundlak (1978), Chamberlain (1984) and Wooldridge (2005) in order to address the initial conditions problem by letting the individual terms $\alpha_{i}$ be correlated with a set of strictly exogenous regressors $\left(\overline{\mathbf{z}}_{i}\right)$ according to the following specification:

$$
\alpha_{i}=\alpha_{0}+\overline{\mathbf{z}}_{i} \delta+\eta_{i}
$$

where $\eta_{i} \sim N\left(0, \sigma_{\eta}^{2}\right)$ is an individual-specific random error term and $\overline{\mathbf{z}}_{i}$ is the average income randomly assigned to subject $i$ during the whole session. The proportion of the total variance contributed by the panel-level variance component $\alpha_{i}$ is given by the following ratio:

$$
\delta=\frac{\sigma_{\eta}^{2}}{\sigma_{\eta}^{2}+1} .
$$

Moreover, we allow the errors of model (4) to follow a first-order autoregressive AR(1) process:

$$
u_{i t}=\rho u_{i t-1}+\epsilon_{i t}
$$

The estimation is performed using Simulated Maximum Likelihood methods, as in Hyslop (1999) and Stewart (2006). Since we employ (in most specifications) a nonlinear model, we will focus our discussion of the results on marginal effects, which are computed using delta methods (Bartus et al. 2005).

\subsection{Identification of endogenous social effects}

Before turning to the results, we discuss a number of issues related to the identification of endogenous social effects. In a seminal paper, Manski (1993) describes the challenges with identification of social effects. There are three hypotheses to explain why individuals belonging to the same group tend to behave similarly. First, the propensity of an individual to behave in some way can vary with the behavior of the group. This is called a "social endogenous effect", and it is the effect that we are after. Second, the propensity of an individual to behave in some way can vary with the exogenous characteristics of the group. This is called "social exogenous or contextual effect". Finally, individuals in the same group tend to behave similarly because they have similar individual characteristics or face similar institutional environments. These are called "correlated" effects. Clearly, the presence of correlated effects can confound

\footnotetext{
${ }^{20}$ This helps controlling for wealth effects that could affect compliance behavior since, at the end of each round, participants receive information of their net income, after taxes and after possible fines are charged.
} 
the identification of social effects. Moreover, even in the absence of correlated effects, simultaneity in behavior of interacting agents can cause the so-called "reflection problem", and hinder the identification of the endogenous from the exogenous social effects.

In Section 2.2, we advanced a number of hypothesis (guilt/pride, internalization of social norms, fear of audit surge, uncertainty about tax enforcement) on why endogenous social effects can play an important role in the individual tax evasion decision. By controlling for the type of information, official or unofficial, that subjects receive, as well as by observing the content of the information that is communicated, our experiment design allows us to identify how the behavior of the other subjects affects an individual income reporting behavior. In the following, we discuss in detail how specific characteristics of the experiment design, as well of the econometric methodology adopted, allow for the identification of the endogenous social effects.

Reference groups. As in Fortin et al. (2007), reference groups are naturally defined as participants in each particular session. There are two characteristics of our experimental design that limit correlated effects and sorting biases: we randomize participants across groups, and we randomize the location of each participant in the experimental lab. This latter measure reduces the possibility that informal chats between participants, although not permitted, may drive the correlated behavior.

Individual effects. We control for individual random effects to capture all the time-invariant individualspecific observed and unobserved characteristics. We could have taken a similar route, as in Fortin et al. (2007), and included group fixed effects. To the extent that correlated individual effects are timeinvariant, the inclusion of group fixed effects would clearly help identifying the endogenous and exogenous interactions effects. We decided to be even more demanding and include subject fixed effects in the linear probability model as a robustness check. It is important to realize that including subject fixed effects, given the experimental design, is stronger than including group fixed effects. Group fixed effects would capture the time-invariant forces that are common to the members of a group. Since each subject belongs to only one group, individual fixed effects play the same role. However, using individual — as opposed

to group - fixed effects controls for correlated effects that have an heterogeneous impact on different members of the same group. On top of that, individual effects also capture purely individual-specific time-invariant forces, like risk-aversion or intrinsic motivations to pay (or not to pay) taxes in full.

Dynamic model. In the experiment we "treat" some participants by informing them on a measure of evasion intensity of the group in the previous period. However, there could still be indirect contemporaneous simultaneity effects deriving from persistence in individual evasion behavior. We model this possibility directly by estimating a dynamic model where the participant's evasion behavior in $t-1$ and/or in $t-2$ can affect her behavior in $t$. Moreover, we allow the variance-covariance matrix of the errors to follow an autoregressive structure (see equation 7 ).

\section{Results}

In this section we apply the econometric model to our experimental data. In the first part of the section, we focus on the identification of social interactions effects, and consider how information on the degree of tax compliance of others affects an individual propensity to underreport income. We consider 
both types of information treatments described above - "official" and "unofficial" - and allow for different interpretations on how individuals may process the informational content received. We focus on the effect of information on the dichotomous decision to evade or comply, but we also provide additional results regarding the effect of information on evasion intensity, i.e. the share of unreported income. Finally, we show that our baseline results are confirmed when - instead of using the dynamic generalized equations model described in the previous section - we pool treatment and control observations and resort to a difference-in-differences (DD) approach.

In the second part of the section we pool all observations - Treatment A, Treatment B, and Control - to revisit and extend some results found in the literature, i.e. we evaluate the importance of persistence in tax compliance, the "bomb-crater" effect, as well as the higher propensity to evade for taxpayers that are slightly above the tax rate threshold.

Finally, in the last part of the section, we show that, besides affecting individual decisions, the provision of information has a substantial effect on the aggregate evasion intensity and share of evaders.

\subsection{The effect of official and unofficial information on the propensity to evade}

We start by studying the effect of official information on the propensity to evade. In order to do that, we augment the econometric model presented in equation 4 with an additional covariate, $A V E_{t}$, capturing the information - provided to each subject at time $t$-about the average evasion intensity of all session participants in the previous round,

$$
\begin{gathered}
y_{i t}^{*}=\gamma y_{i t-1}+\mathbf{x}_{\mathbf{i t}}^{\prime} \boldsymbol{\beta}+\varphi A V E_{t}+\alpha_{i}+u_{i t}, \\
y_{i t}=1\left[y_{i t}^{*}>0\right] .
\end{gathered}
$$

Since we are estimating a nonlinear model, we focus our discussion on the average marginal effects associated to the main variable of interests, and we refer the reader to Appendix B.3 for tables containing all the coefficient estimates.

The left panel of Table 4 reports the average marginal effect of communicating the $t-1$ average evasion intensity, $A V E_{t}$, on the probability to evade in $t{ }^{21}$ The first column shows that the overall effect is not significant, while the second and third columns - where we interact $A V E_{t}$ with a dummy variable equal to one if subject $i$ had evaded at time - hint to the possibility that the effect might work in opposite directions for those subjects that had evaded in $t-1$ ("evaders"), and those that had complied in $t-1$ ("compliants"). This is confirmed in column 4 and 5 of the left panel, where we show that the higher the official past tax evasion rate the higher the degree of persistence: evaders are more likely to evade again, and compliants are more likely to comply again. More precisely, we show that the effect depends on the relative position, in terms of evasion in $t-1$, of the subject with respect to the population. In the case of "evaders", we find that a one percentage point increase in the official evasion rate corresponds to 2.1 percentage points increase in the subject's probability to evade when the subject had evaded in

\footnotetext{
${ }^{21}$ The table reports average marginal effects for our main variables of interests. The controls include the first and second lag of the dependent variable, a dummy variable equal to one if the subject had been audited in $(t-1)$, a dummy variable equal to one if the subject had been audited in $(t-2)$, the subject's income in $t$, earnings in $(t-1)$, and cumulated earnings up to $(t-1)$, a dummy variable equal to one if the subject's income in $t$ is up to 100 euro above the relevant tax rate, a control for the number of rounds already played, and a series of dummy variables equal to one if the subject is male, over 24 years old, and unemployed.
} 
Table 4: Estimates of the effect of official and unofficial information on the probability of evasion Average marginal effects

\begin{tabular}{|c|c|c|c|c|c|c|c|c|c|}
\hline & \multicolumn{5}{|c|}{ Official information (Treatment A) } & & \multicolumn{3}{|c|}{ Unofficial information (Treatment B) } \\
\hline & All & Compliants in $t-1$ & Evaders in $t-1$ & Compliants in $t-1$ & Evaders in $t-1$ & & All & Compliants in $t-1$ & Evaders in $t-1$ \\
\hline \multirow[t]{2}{*}{ Average evasion intensity in $\mathrm{t}-1\left(A V E_{t}\right)$} & 0.111 & -0.189 & 0.427 & & & All peers evaded in $t-1$ & $0.286^{* * *}$ & $0.401^{* * *}$ & $0.154^{* *}$ \\
\hline & $(0.336)$ & $(0.355)$ & $(0.506)$ & & & & $(0.092)$ & $(0.154)$ & $(0.070)$ \\
\hline \multirow[t]{2}{*}{ *Lower than own evasion } & & & & n.a. & -0.203 & All peers complied in $t-1$ & -0.044 & 0.052 & $-0.153^{* * *}$ \\
\hline & & & & n.a. & $(0.702)$ & & $(0.054)$ & $(0.099)$ & $(0.055)$ \\
\hline \multirow[t]{2}{*}{$\begin{array}{c}* \begin{array}{l}\text { Higher than own evasion } \\
\text { Gap below median }\end{array}\end{array}$} & & & & $-2.967^{* *}$ & $2.089^{* *}$ & & & & \\
\hline & & & & $(1.402)$ & $(0.967)$ & & & & \\
\hline \multirow[t]{2}{*}{$\begin{array}{c}* \text { Higher than own evasion } \\
\text { Gap above median }\end{array}$} & & & & -0.906 & $3.536^{*}$ & & & & \\
\hline & & & & $(0.920)$ & (1.893) & & & & \\
\hline Subject-period controls & Yes & Yes & Yes & Yes & Yes & & Yes & Yes & Yes \\
\hline Observations & 580 & 580 & 580 & 580 & 580 & & 520 & 520 & 520 \\
\hline
\end{tabular}

Notes: An observation is a subject-period pair. This table reports the average marginal effects for selected variables from the dynamic probit model of Section 5 when applied to observations from Treatment A (left panel) and B (right panel) sessions. The dependent variable is a dummy equal to one when the subject underreports her income in $t$, and zero otherwise. Subject-period controls include the following variables: gross income (before taxes and fines) received at time $t$; net income (after taxes and fines) earned at the end of round $t-1$; total net income, at the beginning of round $t$, cumulated from the beginning of the session; a dummy variable equal to one when the current gross income of the subject is 100 euros above the threshold of the assigned tax rate; a dummy variable equal to one when the subject was audited in $t-1$ and zero otherwise, and a similar dummy for being audited in $t-2$; the number of periods since the beginning of the session; a dummy variable equal to one if the subject is unemployed; a dummy variable equal to one if the subject is more than 24 years old; a dummy variable equal to one if the subject is male. The definition of all variables can be found in Appendix B Standard errors robust to serial correlation in parentheses, statistically significant at the $1 \%(* * *), 5 \%(* *), 10 \%(*)$ level.

$t-1$ somewhat less than the average. The effect is stronger, 3.5 percentage points, when the subject had evaded in $t-1$ much less than the average ${ }^{22}$ For those evaders that had evaded more than the official evasion rate we do not find any significant effect. In the case of "compliants", we find that a one percentage point increase in the official evasion rate corresponds to 3 percentage points reduction in the subject's probability to evade when the subject had evaded in $t-1$ somewhat less than the average - which, in the case of compliants, corresponds to a low average evasion rate. Both in the case of a gap between the official evasion rate and a subject's own evasion rate below or above the median, a test of the contrast shows that the marginal effects of evaders and compliants are significantly different at 5 percent or less.

A simple way to rationalize this behavior is to refer to the theory that feelings of guilt or shame can affect tax compliance (Brian Erard, 1994, Andreoni et al., 1998; Luttmer and Singhal, 2014). If cheating on taxes causes ex-post feelings of guilt or shame, a subject that declared less than her actual income in $t-1$ may be more likely to keep evading if she knows that evasion is pervasive among the other subjects. On the contrary, we could expect a reverse effect if compliance generates feelings of proudness

\footnotetext{
${ }^{22}$ Specifically, we consider the median of the distribution (over all subjects and periods) of the (positive) difference between the official average evasion rate in $t-1$ and a subject's own evasion rate in $t-1$. We then split subjects into three groups: those that had evaded more than the official rate, those that had evaded less than the official rate but whose difference with the official rate is less than the median, and those that had evaded less than the official rate but whose difference with the official rate is higher than the median.
} 
Figure 3: Cumulated number of messages received and share of compliants, by round

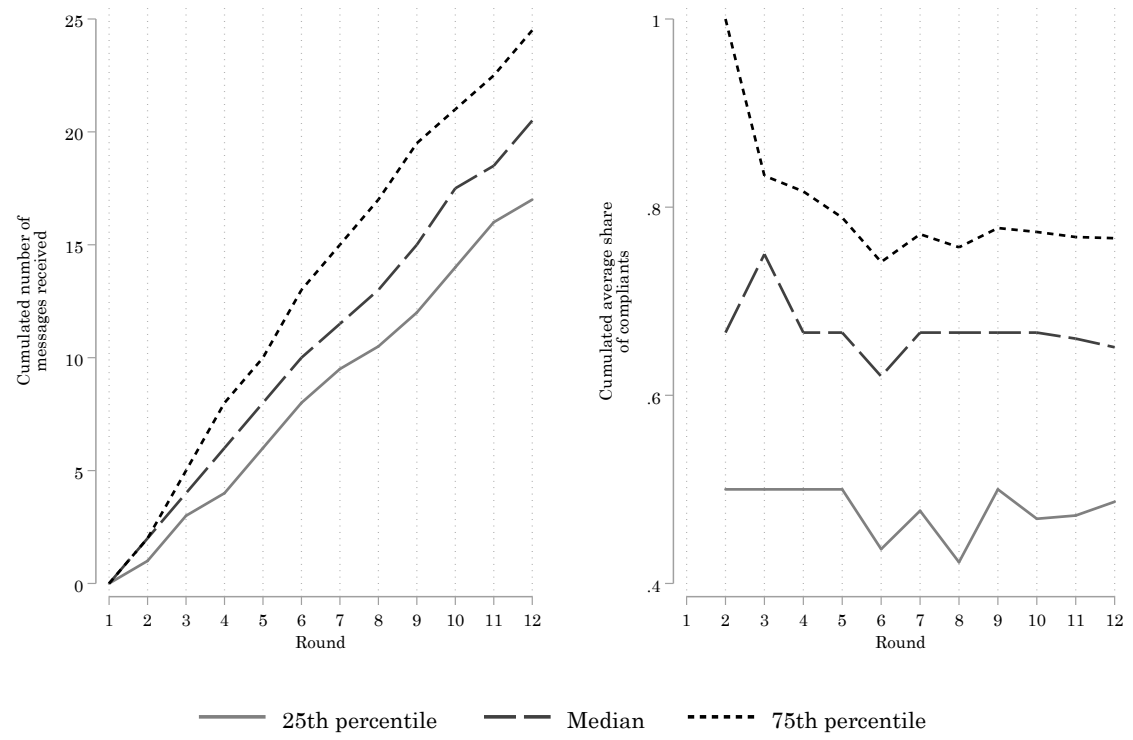

Notes: The figure, shows the $25^{t h}, 50^{t h}$, and $75^{t h}$ percentiles of the distribution of the number of messages received (left panel), and of the distribution of the share of compliants communicated via messages, by round.

that are enhanced by the information that the other subjects are behaving "incorrectly". This result is also reminiscent of Dwenger et al. (2016) who consider a treatment in which those paying at least the required amount of the local Protestant church tax have a probability of having their names published in a local newspaper, should they wish to. The authors find that this treatment reduces payments for those who had evaded the church tax in the past, while it increases payments for all others, indicating that intrinsic motivation is an important factor in tax compliance. The fact that we do not find any significant increase in the probability to comply when the evasion rate in $t-1$ is high can be interpreted as a dissolution of the pride effect in high evasion contexts. ${ }^{23}$

We now turn to the effect of unofficial information on the probability to evade. In this treatment subjects were partitioned in groups of four, and they could receive messages from the other members of the group regarding their reporting behavior in $t-1$. Figure 3 shows that the median subject received 20 messages by the end of the session (left panel), and that there was quite some variation in the share of messages reporting compliance behavior (right panel).

We consider two clear-cut extreme cases of peer communication: subjects that received messages of evasion from all their peers, and subjects that received messages of compliance from all their peers - again allowing for an heterogeneous impact of peer communication on subjects that had complied or had evaded

\footnotetext{
${ }^{23}$ As we mentioned above, an alternative hypothesis could be that the information about the official evasion rate affects a subject's perception of the probability of being audited. However, this hypothesis is not likely to hold in the data given that we made it very clear that the probability of being audited was constant throughout the whole experiment. Moreover, even if there were a residual increase in the perception of the probability of being audited when the official evasion rate is high, this would not be consistent with the data, as we find that in those cases "evaders" tend to evade more.
} 
in $t-1$. In practice, we augment the econometric model presented in equation 4 with an additional covariate, $P E_{i t}$, equal to one if subject $i$ at time $t$ receives messages from all her peers communicating that each of them had evaded (or complied) in the previous round,

$$
\begin{gathered}
y_{i t}^{*}=\gamma y_{i t-1}+\mathbf{x}_{\mathbf{i t}}^{\prime} \boldsymbol{\beta}+\varphi P E_{i t}+\alpha_{i}+u_{i t}, \\
y_{i t}=1\left[y_{i t}^{*}>0\right] .
\end{gathered}
$$

We also consider the interaction of $P E_{i t}$ with a dummy variable equal to one if subject $i$ had evaded at time $t-1$, similarly to what we had done before while considering the official information case.

The right panel of Table 4 shows that, whenever a subject's peers all declare to have evaded in the previous round, the probability of the subject's herself evading is higher. This effect applies both to subjects that had evaded and to subjects that had complied in $t-1$, but it is particularly strong for subjects that had complied in $t-1$, consistently with the raw data evidence of Table 3 . On the contrary, the right panel of table 4 shows that, whenever a subject's peers all declare to have complied in the previous round, the probability of the subject's herself complying is higher if the subject had evaded in $t-1$. The effect on subjects that had already complied in $t-1$ is instead not significant. The magnitude of the effects is large. Receiving the message that all peers evaded increases the probability of a subject evading herself by between 15 and 40 percentage points. On the contrary, receiving a message of full peer compliance decreases the probability of evasion by 15 percentage points, for subjects who had evaded previously.

Our empirical results show that the effect of unofficial information on tax behavior is consistent with the theoretical model laid out in Section 2 with a simple qualification: subjects that had evaded in $t-1$ persist in their behavior whenever they know that their peers also evaded, and are less likely to evade - or switch to compliance - whenever they know that their peers complied. Their behavior is consistent with the case of strategic intertemporal complementarities (in the language of Proposition 3) increasing with the degree of communicated evasion, as depicted by Figure 1a. On the contrary, subjects that had complied in $t-1$ persist in their behavior whenever they know that their peers also complied, and are less likely to comply - or switch to evasion - whenever they know that their peers evaded. Their behavior is consistent with the case of strategic intertemporal complementarities (in the language of Proposition 3) decreasing with the degree of communicated evasion, as depicted by Figure 1b. A way to rationalize this dichotomy is to acknowledge that - besides feelings of guilt or shame - the tax behavior of subjects in the unofficial information case can be affected by group identification. When taxpayers identify with the group of subjects they receive information about they might internalize their social norms and act concurrently 24 In the context of the unofficial information treatment-where subjects can send and receive messages within a small group of peers with which they interact for 12 consecutive rounds - group identification can definitely be stronger than in the official information treatment.

\subsubsection{Robustness Checks and Extensions}

In the previous section we showed that official and unofficial information have qualitatively different effects on the probability of evasion, and that their effects are sizeable. In this section we perform two

\footnotetext{
${ }^{24}$ Wenzel $(2004)$ emphasizes the role of social identification as a process transforming a social group into a self-category and reference group whose norms are internalized and acted upon as one's own personal views.
} 
robustness checks and one extension of our baseline results. First, we show that our baseline results are confirmed when — instead of using the dynamic generalized equations model — we pool treatment and control observations and resort to a difference-in-differences (DD) approach. Second, we consider the unifying theory that the crucial element that affects subjects' tax compliance behavior is their belief about the share of evaders in their reference group, and that they use the information received-be it official or unofficial - to update their beliefs in a Bayesian fashion. Third, we switch our focus from the probability to evade and its persistence to evasion intensity, and consider how information on the degree of tax compliance of others affects an individual propensity to underreport income. All the results, whenever significant, reinforce the baseline findings of the previous section.

Difference-in-differences Estimates As a first robustness check, we construct two new samples: the first one - Sample A-pools the observations of Treatment A and of the control sessions together; the second sample - Sample B - pools the observations of Treatment B and of the control sessions together. We use Sample A to re-estimate the specifications of Table 4 using a linear probability model 25 In practice, we run a difference-in-differences estimation where the effect of the average evasion intensity on the probability of the subject evading in $t$ is identified through the assumption that, in the absence of the treatment, subjects would behave as in the control group.

There are advantages and disadvantages from using linear probability models instead of the dynamic random correlated effects probit models of Section 5. Linear probability models are more robust, than random effects probit models, to the form of unobserved heterogeneity, and they avoid the problem of the initial conditions of the dynamic process, i.e. they eliminate the incidental parameters associated with the unobserved heterogeneity. However, linear probability models do not constraint the predicted probabilities of evasion to the unit interval, and nonlinear models are more likely to provide a better fit. Moreover, to the extent that the assumptions regarding the distribution of $\alpha_{i}$ and $u_{i}$ are correct, nonlinear models provide stronger identification and higher efficiency. Furthermore, with the Probit model the heteroskedasticity of the error term is directly modeled in the likelihood function, whereas with the linear probability model the estimates of the standard errors need to be corrected ex-post in order to make them robust to heteroskedasticity. Reassuringly, in our case, both estimation approaches produce qualitatively similar results, as shown in Table 5 .

\footnotetext{
${ }^{25}$ We augment the specifications by including a dummy variable equal to one for the observations of Treatment $\mathrm{A}$ and by setting to zero the average evasion intensity officially communicated $\left(A V E_{i t}\right)$ for the observations of the control group, i.e., we use the missing-indicator method to deal with such missing data.
} 
Table 5: Estimates of the effect of official and unofficial information on the probability of evasion - Linear probability model difference-in-differences estimates

Official information (Treatment A)

Compliants in $t-1 \quad$ Evaders in $t-1$

Unofficial information (Treatment B)

Compliants in $t-1 \quad$ Evaders in $t-1$

Average evasion intensity in $\mathrm{t}-1\left(A V E_{t}\right)$

$\begin{array}{lcc}* \text { Lower than own evasion } & \text { n.a. } & -0.222 \\ & \text { n.a. } & (0.608) \\ * \begin{array}{l}\text { Higher than own evasion } \\ \text { Gap below median }\end{array} & -3.033^{*} & 2.066^{* *} \\ & (1.764) & (0.879) \\ \text { Higher than own evasion } & & \\ \quad \text { Gap above median } & -0.727 & 3.458^{*} \\ & (0.798) & (1.961)\end{array}$

All peers evaded in $\mathrm{t}-1$

All peers complied in t-1

Subject-period controls

Observations

$\begin{array}{cc}0.399^{* * *} & 0.190^{* *} \\ (0.144) & (0.092) \\ 0.010 & -0.127 \\ (0.097) & (0.250)\end{array}$

Yes Yes

$\begin{array}{cc}\text { Yes } & \text { Yes } \\ 888 & 888\end{array}$

$948 \quad 948$

Notes: An observation is a subject-period pair. This table reports the marginal effects for selected variables from the linear probability model of Section 5 when applied to observations from Sample A (Treatment A \& Control, left panel) and Sample B (Treatment B \& Control, right panel) sessions. The dependent variable is a dummy equal to one when the subject underreports her income in $t$, and zero otherwise. Subject-period controls include the following variables: gross income (before taxes and fines) received at time $t$; net income (after taxes and fines) earned at the end of round $t-1$; total net income, at the beginning of round $t$, cumulated from the beginning of the session; a dummy variable equal to one when the current gross income of the subject is 100 euros above the threshold of the assigned tax rate; a dummy variable equal to one when the subject was audited in $t-1$ and zero otherwise, and a similar dummy for being audited in $t-2$; the number of periods since the beginning of the session; a set of dummy variables controlling for the type of treatment ( $\mathrm{A}, \mathrm{B}$, or control); a dummy variable equal to one if the subject is unemployed; a dummy variable equal to one if the subject is more than 24 years old; a dummy variable equal to one if the subject is male. The definition of all variables can be found in Appendix B Standard errors robust to serial correlation in parentheses, statistically significant at the $1 \%(* * *), 5 \%(* *), 10 \%(*)$ level.

A Bayesian Interpretation of the Information on Tax Evasion As a second robustness check, we propose a unifying theory of our empirical results. We conjecture that the crucial element that affects subjects' tax compliance behavior is the belief about the share of evaders in their reference group, and that they use the information received-be it official or unofficial - to update their beliefs. Beliefs are 
updated in a Bayesian fashion using all the information received in the previous rounds. Even though we have already shown that official and unofficial information have qualitatively different effects on tax compliance, the following exercise provides a complementary and more direct quantitative comparison between the two treatments.

Using the notation introduced in section 2.2, we model $\Omega_{t-1}$ in the spirit of Jovanovic (1982), and assume that there exists a "true" underlying share of evaders $\theta_{g}$ in the reference group. We assume that all the subjects share the same prior regarding $\theta_{g}$ and that the prior is distributed $\operatorname{Beta}(\alpha, \beta) .{ }^{26}$ Consider a subject receiving $n$ messages, indexed by $m$, regarding the share of unreported income of members of her reference group. If the share of unreported income is above some threshold the subject regards the message as signalling an evasion behavior, $x_{m}=1$, and as signalling a compliant behavior otherwise, $x_{m}=0$. We assume that each subject consider the overall information received as resulting from a Binomial distribution with $n$ trials and probability of success $\theta_{g}$. Using Bayes' Theorem, the posterior distribution $\mu(\cdot)$, of the share of evaders is also Beta distributed 27

$$
\tilde{\mu}\left(\theta_{g} \mid\left\{x_{m}\right\}_{m=1}^{n}, n, \alpha, \beta\right) \sim B\left(\alpha+\sum_{m=1}^{n} x_{m}, \beta+n-\sum_{m=1}^{n} x_{m}\right),
$$

where $B($.$) is the Beta distribution. Then, the posterior mean can be computed as$

$$
E\left[\theta_{g} \mid\left\{x_{m}\right\}_{m=1}^{n}, n, \alpha, \beta\right]=\frac{\frac{\alpha}{n}+\bar{x}}{\frac{\alpha+\beta}{n}+1},
$$

where $\bar{x}=\sum_{m=1}^{n} x_{m} / n$ is the cumulated share of evasion signals received, while the posterior standard deviation is

$$
\tilde{\sigma}\left[\theta_{g} \mid\left\{x_{m}\right\}_{m=1}^{n}, n, \alpha, \beta\right]=\frac{1}{\alpha+\beta+n} \sqrt{\frac{\left(\frac{\alpha}{n}+\bar{x}\right)\left(\frac{\beta}{n}+1-\bar{x}\right)}{\frac{\alpha+\beta+1}{n}+1} .}
$$

We can then compute $\tilde{\mu}$ and $\tilde{\sigma}$ for each subject and period, both in the official and unofficial treatments, and used them as covariates in the dynamic probit model, interpreting $\tilde{\mu}$ as the subject's belief regarding the share of evaders in the reference group, and the inverse of $\tilde{\sigma}$ as an additional control for the precision of the belief ${ }^{28}$ In practice, we augment the econometric model presented in equation 4 as follows,

$$
\begin{gathered}
y_{i t}^{*}=\gamma y_{i t-1}+\mathbf{x}_{\mathbf{i t}}^{\prime} \boldsymbol{\beta}+\varphi \tilde{\mu}_{i t} \times \tilde{\sigma}_{i t}^{-1} \times \mathcal{I}\left(F_{i t-1}=1\right)+\alpha_{i}+u_{i t}, \\
y_{i t}=1\left[y_{i t}^{*}>0\right],
\end{gathered}
$$

\footnotetext{
${ }^{26} \mathrm{~A}$ special case is when the prior is uniformly distributed over the unit interval $[0,1]$, which is equivalent to assuming a Beta $(1,1)$ distribution. In practice, we calibrate $\alpha$ and $\beta$ to match the mean and standard deviation of the share of evaders in the control group (see Table 1). Results using the alternative Beta $(1,1)$ prior distribution are qualitatively similar and available upon request.

${ }^{27}$ This corresponds to the well known "beta-binomial" model. The beta prior is conjugate to the binomial likelihoods.

${ }^{28}$ Controlling for the precision of the belief allows us to control for differences in the size of the reference group between Treatment $\mathrm{A}$ and $\mathrm{B}$. In the unofficial information treatment $n$ corresponds to the number of messages received by a subject up to the current round, while $x$ is equal to 1 whenever the message informs that the peer evaded more than 10 percent of his income in the previous round. In the official information treatment we interpret the communicated average evasion intensity in the previous round as multiple equal messages, whose number is equal to the number of session participants. The content of the message, $x$ is again equal to 1 whenever the communicated average evasion intensity was higher than 10 percent.
} 
Table 6: Bayesian Posterior Mean - Average marginal effects

\begin{tabular}{|c|c|c|c|c|c|c|}
\hline & \multicolumn{3}{|c|}{ Official information } & \multicolumn{3}{|c|}{ Unofficial information } \\
\hline \multirow{3}{*}{ Posterior mean share of evaders $\left(\tilde{\mu}_{i t}\right)$} & All & Compliants in $t-1$ & Evaders in $t-1$ & All & Compliants in $t-1$ & Evaders in $t-1$ \\
\hline & $0.478^{* *}$ & $0.373^{*}$ & $0.623^{*}$ & 0.076 & -0.103 & $0.282^{*}$ \\
\hline & $(0.231)$ & $(0.222)$ & $(0.334)$ & $(0.096)$ & $(0.125)$ & $(0.150)$ \\
\hline Subject-period controls & Yes & Yes & Yes & Yes & Yes & Yes \\
\hline Observations & 580 & 580 & 580 & 520 & 520 & 520 \\
\hline
\end{tabular}

Notes: An observation is a subject-period pair. This table reports the average marginal effects for selected variables from the dynamic probit model of Section 5 when applied to observations from Treatment A (left panel) and B (right panel) sessions. The dependent variable is a dummy equal to one when the subject underreports her income in $t$, and zero otherwise. Subject-period controls include the following variables: the posterior standard deviation $\tilde{\sigma}$ of the belief on the share of evaders in the reference group; gross income (before taxes and fines) received at time $t$; net income (after taxes and fines) earned at the end of round $t-1$; total net income, at the beginning of round $t$, cumulated from the beginning of the session; a dummy variable equal to one when the current gross income of the subject is 100 euros above the threshold of the assigned tax rate; a dummy variable equal to one when the subject was audited in $t-1$ and zero otherwise, and a similar dummy for being audited in $t-2$; the number of periods since the beginning of the session; a dummy variable equal to one if the subject is unemployed; a dummy variable equal to one if the subject is more than 24 years old; a dummy variable equal to one if the subject is male. The definition of all variables can be found in Appendix B Standard errors robust to serial correlation in parentheses, statistically significant at the $1 \%(* * *), 5 \%(* *), 10 \%(*), 12 \%\left(^{+}\right)$level.

where $\mathcal{I}\left(F_{i t-1}=1\right)$ is an indicator variable equal to one if subject $i$ had evade in the previous period, and $\times$ represents an interaction between two or more covariates.

Table 6 shows that the results of this exercise are consistent with those of Table 4. We find that an increase of 1 percentage point in the beliefs regarding the share of evaders increases the probability of evasion by 0.62 percentage points for those subjects that had evaded in $t-1$ in the official information case, and by 0.28 percentage points for those subjects that had evaded in $t-1$ in the unofficial information case. The positive effect of the belief about the share of evaders on the evasion propensity of "evaders", both in the official and unofficial information case, is consistent with the results and interpretations outline above. The fact that the coefficient for the unofficial information case is smaller than the one of the official information case could be due to the presence of measurement error, due to the possibility that the messages received from the peers might contain false information. The coefficient for those subjects that had complied in $t-1$ is instead not significant in the unofficial information case, and barely significant in the official information case. When we allow the effect of official information to depend on the relative positioning, in terms of evasion rate in $t-1$, of the subject with respect to the official average evasion intensity we find that compliants are more likely to comply when they observe an evasion rate that is not too high (below the median), similar to what we found in Section 6.1. 
Table 7: Estimates of the effect of official and unofficial information on the share of unreported income Average marginal effects

\begin{tabular}{|c|c|c|c|c|c|c|c|c|}
\hline & \multicolumn{5}{|c|}{ Official information (Treatment A) } & \multicolumn{3}{|c|}{ Unofficial information (Treatment B) } \\
\hline & All & Compliants in $t-1$ & Evaders in $t-1$ & Compliants in $t-1$ & Evaders in $t-1$ & All & Compliants in $t-1$ & Evaders in $t-1$ \\
\hline \multirow[t]{2}{*}{ Average evasion intensity in $\mathrm{t}-1$} & $-0.315^{* *}$ & $-0.558^{* * *}$ & -0.041 & & & & & \\
\hline & $(0.137)$ & $(0.160)$ & $(0.235)$ & & & & & \\
\hline \multirow[t]{2}{*}{ *Lower than own evasion } & & & & n.a. & -0.306 & & & \\
\hline & & & & n.a. & $(0.351)$ & & & \\
\hline \multirow[t]{2}{*}{ *Higher than own evasion } & & & & $-2.063^{* * *}$ & 0.191 & & & \\
\hline & & & & $(0.797)$ & $(0.447)$ & & & \\
\hline \multirow[t]{2}{*}{${ }^{*}$ Much higher than own evasion } & & & & -0.365 & $1.224^{* *}$ & & & \\
\hline & & & & $(0.261)$ & $(0.555)$ & & & \\
\hline \multirow[t]{2}{*}{ All peers evaded in $\mathrm{t}-1$} & & & & & & 0.094 & 0.099 & 0.089 \\
\hline & & & & & & $(0.083)$ & $(0.075)$ & $(0.103)$ \\
\hline \multirow[t]{2}{*}{ All peers complied in $\mathrm{t}-1$} & & & & & & -0.013 & -0.008 & -0.019 \\
\hline & & & & & & $(0.023)$ & $(0.035)$ & $(0.033)$ \\
\hline Subject-period controls & Yes & Yes & Yes & Yes & Yes & Yes & Yes & Yes \\
\hline Observations & 580 & 580 & 580 & 580 & 580 & 520 & 520 & 520 \\
\hline
\end{tabular}

Notes: An observation is a subject-period pair. This table reports the average marginal effects for selected variables from the dynamic model of Section 5 when applied to observations from Treatment A (left panel) and B (right panel) sessions. The dependent variable is the share of unreported income. Subject-period controls include the following variables: gross income (before taxes and fines) received at time $t$; net income (after taxes and fines) earned at the end of round $t-1$; total net income, at the beginning of round $t$, cumulated from the beginning of the session; a dummy variable equal to one when the current gross income of the subject is 100 euros above the threshold of the assigned tax rate; a dummy variable equal to one when the subject was audited in $t-1$ and zero otherwise, and a similar dummy for being audited in $t-2$; the number of periods since the beginning of the session; a dummy variable equal to one if the subject is unemployed; a dummy variable equal to one if the subject is more than 24 years old; a dummy variable equal to one if the subject is male. The definition of all variables can be found in Appendix B Standard errors robust to serial correlation in parentheses, statistically significant at the $1 \%(* * *), 5 \%(* *), 10 \%(*)$ level.

The Effect of Official and Unofficial Information on Evasion Intensity As a final exercise, we switch the focus from the probability to evade to the extent of the evasion - i.e. on evasion intensity - and consider how information on the degree of tax compliance of others affects an individual propensity to underreport income, by considering a linear version of the dynamic model (1), instead of the probit specification considered before. Table 7 reports all the results, and shows that all the qualitative results of the baseline exercise are confirmed, even though we loose some significance. In the case of official information, we find that a one percentage point increase in the official evasion rate corresponds to 1.2 percentage points increase in the subject's evasion intensity when the subject had evaded in $t-1$ much less than the average. In the case of "compliants", we find that a one percentage point increase in the official evasion rate corresponds to 2.1 percentage points reduction in the subject's evasion intensity when the subject had evaded in $t-1$ somewhat less than the average - which, in the case of compliants, corresponds to a low average evasion rate. In the case of unofficial information we find, as in Section 
Table 8: Persistence in tax evasion, and bomb-crater effect - Average marginal effects, pooled sample

\begin{tabular}{|c|c|c|c|c|c|c|c|}
\hline & \multicolumn{3}{|c|}{ Persistence } & & \multicolumn{3}{|c|}{ Bomb-crater effect } \\
\hline & Overall & Compliants in $t-2$ & Evaders in $t-2$ & & Overall & Compliants in $t-1$ & Evaders in $t-1$ \\
\hline \multirow[t]{2}{*}{ Evaded in $t-1$} & $0.363^{* * *}$ & $0.445^{* * *}$ & $0.250^{* * *}$ & Audited in $t-1$ & $0.050^{*}$ & $0.070^{* *}$ & 0.022 \\
\hline & $(0.029)$ & $(0.042)$ & $(0.048)$ & & $(0.030)$ & $(0.035)$ & $(0.053)$ \\
\hline \multirow[t]{2}{*}{ Evaded in $t-2$} & $0.227^{* * *}$ & & & Audited in $t-2$ & -0.005 & & \\
\hline & $(0.031)$ & & & & $(0.027)$ & & \\
\hline Subject-period controls & Yes & Yes & Yes & Subject-period controls & Yes & Yes & Yes \\
\hline Observations & 1468 & 1468 & 1468 & Observations & 1468 & 1468 & 1468 \\
\hline
\end{tabular}

Notes: An observation is a subject-period pair. This table reports the average marginal effects for selected variables from the dynamic probit model of Section 5 when applied to observations from Treatment A, Treatment B, and Control all pooled together. The dependent variable is a dummy equal to one when the subject underreports her income in $t$, and zero otherwise. Subject-period controls include the following variables: gross income (before taxes and fines) received at time $t$; net income (after taxes and fines) earned at the end of round $t-1$; total net income, at the beginning of round $t$, cumulated from the beginning of the session; a dummy variable equal to one when the current gross income of the subject is 100 euros above the threshold of the assigned tax rate; a dummy variable equal to one when the subject was audited in $t-1$ and zero otherwise, and a similar dummy for being audited in $t-2$; the number of periods since the beginning of the session; a set of dummy variables controlling for the type of treatment (A,B, or control); a dummy variable equal to one if the subject is unemployed; a dummy variable equal to one if the subject is more than 24 years old; a dummy variable equal to one if the subject is male. The definition of all variables can be found in Appendix B Standard errors robust to serial correlation in parentheses, statistically significant at the $1 \%(* * *), 5 \%(* *), 10 \%(*)$ level.

6.1. that subjects that receive the information that all their peers had evaded (complied) are also more likely to increase (decrease) their evasion intensity, even though standard errors are high. Overall, all the results, whenever significant, reinforce the baseline findings of Section 6.1 .

\subsection{State Dependence, Bomb-crater, and Tax Rate Thresholds Effects}

In this second part of the section we pool all observations - Treatment A, Treatment B, and Control - to revisit and extend some results found in the literature, i.e. we evaluate first the importance of persistence in tax compliance, then the so-called "bomb-crater" effect, and finally the higher propensity to evade for taxpayers that are slightly above the tax rate threshold.

State Dependence The left panel of Table 8 confirms the presence of a strong (but time decreasing) state persistence in tax evasion, as already evidenced by the analysis of the transition matrices (Table 2) when discussing the raw data evidence. In particular, the estimated average marginal effect of the dummy variable "Evaded in $t-1$ " is equal to 0.36 and is highly significant, providing strong evidence of true state dependence in evasion. The dynamics of evasion persistence are not limited to lag $t-1$, and evasion decisions in $t-2$ also matter. First, the estimated average marginal effect of the dummy variable "Evaded in $t-2$ " is equal to 0.23 and is highly significant. Second, as shown in columns 2 and 3 of the left panel, the dependence of the decision to evade in the current period on the dummy variable "Evaded 
Table 9: Tax rate threshold effect - Average marginal effects, pooled sample

\section{Tax rate threshold}

Overall $\quad$ Male $\quad$ Female $\quad$ Compliants in $t-1 \quad$ Evaders in $t-1$

$\begin{array}{lccccc}\text { Threshold } & 0.105^{* *} & 0.174^{* *} & 0.040 & 0.148^{* *} & 0.047 \\ & (0.050) & (0.074) & (0.067) & (0.064) & (0.076) \\ & & & & \text { Yes } \\ \text { Subject-period controls } & \text { Yes } & \text { Yes } & \text { Yes } & 1468 & \text { Yes } \\ \text { Observations } & 1468 & 1468 & 1468 & \end{array}$

Notes: An observation is a subject-period pair. This table reports the average marginal effects for selected variables from the dynamic probit model of Section 5 when applied to observations from Treatment A, Treatment B, and Control all pooled together. The dependent variable is a dummy equal to one when the subject underreports her income in $t$, and zero otherwise. Subject-period controls include the following variables: gross income (before taxes and fines) received at time $t$; net income (after taxes and fines) earned at the end of round $t-1$; total net income, at the beginning of round $t$, cumulated from the beginning of the session; a dummy variable equal to one when the current gross income of the subject is 100 euros above the threshold of the assigned tax rate; a dummy variable equal to one when the subject was audited in $t-1$ and zero otherwise, and a similar dummy for being audited in $t-2$; the number of periods since the beginning of the session; a set of dummy variables controlling for the type of treatment (A,B, or control); a dummy variable equal to one if the subject is unemployed; a dummy variable equal to one if the subject is more than 24 years old; a dummy variable equal to one if the subject is male. The definition of all variables can be found in Appendix B Standard errors robust to serial correlation in parentheses, statistically significant at the $1 \%(* * *), 5 \%(* *), 10 \%(*)$ level.

in $t-1$ " depends on the value of the dummy variable "Evaded in $t-2$ ": we find that evasion in $t-1$ has a stronger impact on the decision to evade in the current period when the subject had complied in $t-2$ than when she had evade in $t-2$ as well.

Bomb-crater effect The "bomb-crater" effect, according to which individuals are likely to evade in the period immediately after being audited, was first documented experimentally in Guala and Mittone (2005) and Mittone (2006), and formalized in a social network model of tax compliance by Hashimzade et al. (2014) ${ }^{29}$ In our experiment, we consider the effect of having been audited in $t-1$ or $t-2$ on the conditional predicted probabilities of evasion in $t$ (right panel of Table 8). We find that having been audited in $t-1$ increases the probability of evasion by 5 percentage points, while having been audited in $t-2$ does not seem to have an impact on the current decision to evade. Overall, the magnitude of the estimated effect is small and has somewhat weak statistical significance. We investigate this result further and check if the likelihood of evading immediately after being audited is different between subjects that were audited while evading, and subject that were audited while complying. Our conjecture is that the "bomb-crater" effect should be much stronger in the latter case since subjects who are found to behave

\footnotetext{
${ }^{29}$ Further papers dealing with this phenomenon are Kastlunger et al. (2009) and Maciejovsky et al. (2007).
} 
correctly could, reasonably, expect not to being audited again in the near future 30 Our results are in line with this conjecture. Columns 2 and 3 in the right panel of Table 8 show that the "bomb-crater" effect is observed only among the subjects who had complied in $t-1$. The magnitude is higher and the significance is stronger than for the average subject. This original finding may help future research to shed more light on the dynamics and psychological factors that may explain the "bomb-crater" effect, and may also help to explain why this effect is not always detected in some experimental settings.

Threshold effects The probability of evasion increases when the income $I$ is slightly above the tax-rate change threshold. Column 1 in Table 9 shows that subjects whose incomes are no more than 100 euros higher than the threshold of the assigned tax rate are 11 percentage points more likely to evade. This result is in line with the empirical literature on tax-payers' bunching at kink points. (see, for instance Saez, 2010 and Bastani and Selin, 2014). Further investigation of this result in columns 2 to 5 of Table 9 show that the threshold effect seems to operate mainly for male subjects, and for subjects who had complied in $t-1$.

\subsection{The Aggregate Effect of Information}

We established above that providing information about the past reporting behavior of the population, or of a set of peers, has significant effects on the current behaviors of the taxpayers in our experiment. In a nutshell, we show that, when subjects receive information about the past average evasion rate - what we labelled "official information" - the higher the past average evasion rate the stronger the persistence in income reporting of both evaders and compliants. On the contrary, the sharing of information within a group of peers can alter the stance of taxpayers and, especially, turn compliants into evaders. Both effects operate both at the extensive margin, i.e. the decision of evading or not, and at the intensive margin, i.e. the decision of how much to evade.

In this section we show that, besides affecting individual decisions, the provision of information has substantial aggregate effects. First we show how information affects the aggregate evasion propensity and intensity in the context of our experiment. Second, drawing on the lessons learned in the econometric analysis of the previous section, we discuss how the aggregate effects of information provision can be different in different countries, depending on strength of the propensity to evade and of the peer effects.

The left panel of Figure 4 shows the evolution of the cumulated evasion intensity, i.e. the ratio between the total - over subjects and sessions - unreported income up to period $t$ divided by total income up to period $t$, by treatment type. We normalized, for each sample, the cumulated evasion intensity in the first available period to one, in order to abstract from time-invariant differences in the pool of subjects belonging to each treatment. The right panel of Figure 4 shows instead the cumulated share of underreporting instances, over subjects and sessions, by treatment type. The message, at least in the context of our experiment, is clear: both treatments, and especially the unofficial information treatment, are associated with a significantly larger growth in evasion intensity. Over the course of the experiment,

\footnotetext{
${ }^{30}$ As mentioned above, this effect should not be present, in theory, in our experimental data, since the probability of being audited was exogenous and constant over subjects and periods. Nonetheless, a participant could erroneously or unconsciously believe the probability of being audited to be smaller after having being found to behave correctly. Another possibility is that having being found to behave correctly may make the participant feel to be entitled to deviate - i.e evade - in the next rounds.
} 
Figure 4: Cumulated Evasion Intensity and Share of Evaders, by Treatment

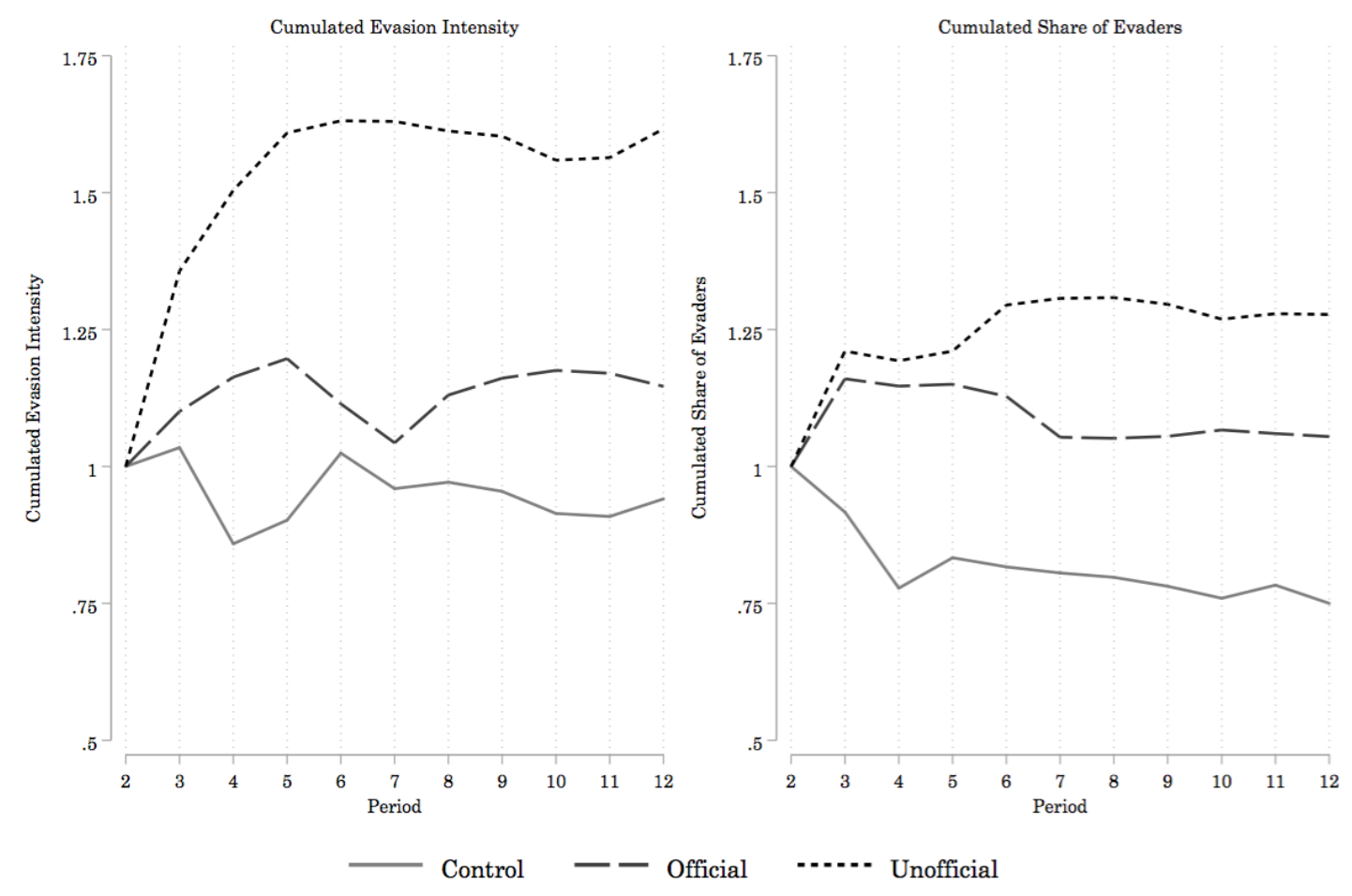

Notes: The figure shows the cumulated weighted average evasion intensity and share of evaders.

the growth in evasion intensity associated to the official and unofficial treatments is, on average, about 65 percent and 25 percent higher, respectively, than that of the control group, which is fairly flat. Part of this differential is due to the extensive margin, i.e. to the larger growth in the share of evaders, as shown in the right panel of Figure 4.

Conditional on the specificities of the experiment, this result calls for attention on the design of instruments that, through the dissemination of information to taxpayers, aim at creating a norm of tax compliance. The results of the econometric analysis of Section 6 suggest that in countries where the propensity to evade is inherently low, official information regarding the level of tax evasion would consolidate the behavior of compliants, who are in the majority, and therefore have beneficial effects. This effect would also be magnified in the presence of strong peer effects. On the contrary, in countries where the propensity to evade is inherently high, official information regarding the level of tax evasion would consolidate the behavior of evaders, who are relatively more, and therefore have detrimental effects. Again, this effect would also be magnified in the presence of strong peer effects.

\section{Concluding remarks}

The administration of tax policy has shifted its focus from enforcement to complementary instruments aimed at creating a social norm of tax compliance (OECD, 2001, and Luttmer and Singhal, 2014). In this paper we provide an analysis of the effects of the dissemination of information regarding the past degree 
of tax evasion on the current tax behavior, and investigate how persistence in tax behavior depends on the channels through which the information is communicated - officially or through peers - and on the target group - past evaders or compliants. Both types of information are increasingly available to taxpayers around the world, and taxpayers are also aware of the tax compliance behavior of their peers.

We build an experiment where, given tax rates, audit probabilities, and fines, subjects have to report their income after receiving either a communication of the official tax evasion rate or messages from their peers about their tax behavior. We use the experimental data to estimate a dynamic econometric model of income reporting, consistent with an Allingham-Sandmo-Yitzhaki tax evasion model extended to include self-consistency and endogenous social interactions among taxpayers. To the best of our knowledge, this is the first paper to discuss peer effects in the context of a dynamic model of tax behavior.

The data show that the decision to comply, i.e. to declare fully your own income, is more persistent than the decision to evade. Persistence in tax behavior - both evasion propensity and intensity-is, however, affected by information on the past behavior of others. Information about a higher evasion rate may push "evaders" to evade again or evade more, and "compliants" to comply again or evade less, when communicated officially, whereas it might increase the likelihood to evade for both groups, when conveyed through peer communication. In the context of our experiment, both treatments, and especially the unofficial information treatment, are associated with a significantly larger growth in evasion intensity. Part of this differential is due to the extensive margin, i.e. to the larger growth in the share of evaders.

This paper sheds light on the discussion of the social and cultural aspects of tax evasion and provides important insights that improve our understanding of the effects that information on past tax behavior has on current compliance levels. From a policy perspective, our results may also provide important suggestions to tax authorities and policy makers by stressing the importance of taking into account the dynamics of evasion persistence when evaluating the consequences of dissemination of information on "social" tax evasion, especially if high evasion rates are going to be communicated to a large pool of potentially persistent evaders. 


\section{References}

Allingham, M. And A. Sandmo (1972): "Income tax evasion: A theoretical analysis," Journal of Public Economics, 1, 323-338. 1, 2

Alm, J., D. M. Bruner, And M. McKee (2016): "Honesty or dishonesty of taxpayer communications in an enforcement regime," Journal of Economic Psychology, 56, 85-96. 15

Alm, J., B. R. Jackson, And M. McKee (2009): "Getting the word out: Enforcement information dissemination and compliance behavior," Journal of Public Economics, 93, 392-402. 1, 3

Alm, J., G. McClelland, And W. Schulze (1992a): "Why do people pay taxes?" Journal of Public Economics, 48, 21-38. 3

Alm, J., G. H. McClelland, And W. D. Schulze (1992b): "Why do people pay taxes?" Journal of public Economics, 48, 21-38. 3.1

Alm, J. AND M. Yunus (2009): "Spatiality and persistence in US individual income tax compliance," National Tax Journal, 101-124. 1

Amir, R. (2005): "Supermodularity and complementarity in economics: An elementary survey," Southern Economic Journal, 636-660. 31

Andreoni, J., B. Erard, And J. Feinstein (1998): "Tax Compliance," Journal of Economic Literature, XXXVI, 818-860. 1, 2.3, 6.1

BALDRY, J. C. (1986): "Tax evasion is not a gamble: A report on two experiments," Economics Letters, 22, 333-335. 1, 3.1

Bartus, T. ET AL. (2005): "Estimation of marginal effects using margeff," Stata journal, 5, 309-329. 5

Bastani, S. And H. Selin (2014): "Bunching and non-bunching at kink points of the Swedish tax schedule," Journal of Public Economics, 109, 36-49. 1. 6.2

Becker, W., H.-J. BüChner, And S. Sleeking (1987): "The impact of public transfer expenditures on tax evasion: An experimental approach," Journal of Public Economics, 34, 243-252. 3

Bénabou, R. And J. Tirole (2011): "Law and norms," NBER Working Paper, 17579. 8

Besley, T. J., A. Jensen, And T. Persson (2015): "Norms, Enforcement, and Tax Evasion," · 8

Brian Erard, J. S. F. (1994): "The Role of Moral Sentiments and Audit Perceptions in Tax Compliance." Public Finance 49: 70-89," Public Finance = Finances publiques, 49, 70-89. 2.3, 6.1

Brock, W. A. And S. N. Durlauf (2001): "Discrete Choice with Social Interactions," The Review of Economic Studies, 68, pp. 235-260. 2.2

Chamberlain, G. (1984): "Panel data," Handbook of Econometrics, ed. Z. Griliches and M. Intrilligator, 2, 1247-1318. 5 
Currarini, S., M. O. Jackson, And P. Pin (2009): "An economic model of friendship: Homophily, minorities, and segregation," Econometrica, 77, 1003-1045. 3.1

Dwenger, N., H. Kleven, I. Rasul, and J. Rincke (2016): "Extrinsic and intrinsic motivations for tax compliance: Evidence from a field experiment in Germany," American Economic Journal: Economic Policy, 8, 203-232. 1, 6.1

Fortin, B., G. Lacroix, and M.-C. Villeval (2007): "Tax evasion and social interactions," Journal of Public Economics, 91, 2089-2112. 1, 2.2, 5.1

Gordon, J. P. (1989): "Individual morality and reputation costs as deterrents to tax evasion," European economic review, 33, 797-805. 1

Guala, F. And L. Mittone (2005): "Experiments in economics: External validity and the robustness of phenomena," Journal of Economic Methodology, 12, 495-515. 2, 6.2

Hashimzade, N., G. D. Myles, F. Page, and M. D. Rablen (2014): "Social networks and occupational choice: The endogenous formation of attitudes and beliefs about tax compliance," Journal of Economic Psychology, 40, 134 - 146, special Issue on Behavioral Dynamics of Tax Evasion. 2, 6.2

Heckman, J. J. (1981): The Incidental Parameters Problem and the Problem of Initial Conditions in Estimating a Discrete Time-Discrete Data Stochastic Process., Cambridge, MA: MIT Press. 5

Hyslop, D. R. (1999): "State dependence, serial correlation and heterogeneity in intertem- poral labor force participation of married women." Econometrica, 1255-1294. 5, 5, 5

Internal Revenue Service (2006): "IRS Updates Tax Gap Estimates," . 1, 3.1

_ (2012): “Tax Gap for Tax Year 2006," · 1, 3.1

_ (2016): “Tax Gap Estimates for Tax Years 2008 -2010," · 1, 3.1

Jovanovic, B. (1982): "Selection and the Evolution of Industry," Econometrica: Journal of the Econometric Society, 649-670. 6.1.1

Kastlunger, B., E. Kirchler, L. Mittone, And J. Pitters (2009): "Sequences of audits, tax compliance, and taxpaying strategies," Journal of Economic Psychology, 30, 405-418. 29

Luttmer, E. F. P. And M. Singhal (2014): “Tax Morale," Journal of Economic Perspectives, 28, 149-68. 1, $2.3,6.1,7$

Maciejovsky, B., E. Kirchler, and H. Schwarzenberger (2007): "Misperception of chance and loss repair: On the dynamics of tax compliance," Journal of Economic Psychology, 28, 678-691. 29

MAnski, C. F. (1993): "Identification of endogenous social effects: The reflection problem," The review of economic studies, 60, 531-542. 1, 5.1.

Matthews, C. (2017): "Here's How Much Tax Cheats Cost the U.S. Government a Year," Fortune. 1. 3.1 
Mittone, L. (2006): "Dynamic behaviour in tax evasion: An experimental approach," The Journal of Socio-Economics, 35, 813-835. 2, 1, 6.2

Moscovici, S. (1961): La psychanalyse, son image et son public: étude sur la représentation sociale de la psychanalyse, Presses universitaires de France. 1

Moscovici, S. And G. Duveen (2000): Social representations: Explorations in social psychology, vol. 41, Polity Press Cambridge. 1

Mundlak, Y. (1978): "On the pooling of time series and cross section data," Econometrica, 46, 69-85. 5

Myles, G. D. And R. A. Naylor (1996): "A model of tax evasion with group conformity and social customs," European Journal of Political Economy, 12, 49-66. 1

OECD (2001): "Principles of Good Tax Administration-Practice Note." Tech. rep., Organization for Economic Co-operation and Development. 1, 7

Povoledo, E. (2011): "Italy Tries to Get Tax Cheats to Pay Up." . 1

SAez, E. (2010): "Do taxpayers bunch at kink points?" American Economic Journal: Economic Policy, 180-212. 1 , 6.2

Snow, A. And R. S. WARren (2005): "Ambiguity about audit probability, tax compliance, and taxpayer welfare," Economic Inquiry, 43, 865-871. 2.3

Soliman, A., P. Jones, And J. Cullis (2014): "Learning in experiments: Dynamic interaction of policy variables designed to deter tax evasion," Journal of Economic Psychology, 40, 175 - 186, special Issue on Behavioral Dynamics of Tax Evasion. 1

Stewart, M. (2006): "Maximum simulated likelihood estimation of random-effects dynamic probit models with autocorrelated errors," The Stata Journal, 6, 256-272. 5. 5

Swedish Tax Agency (2014): "Taxes in Sweden 2014 - An English Summary of Tax Statistical Yearbook of Sweden," Tech. rep., Swedish Tax Agency. 1, 3.1

Wenzel, M. (2004): "An Analysis of Norm Processes in Tax Compliance,," Journal of Economic Psychology, 25, 213-228. 9, 24

Wooldridge, J. M. (2005): "Simple solutions to the initial conditions problem in dynamic, nonlinear panel data models with unobserved heterogeneity," Journal of Applied Econometrics, 20, 39-54. 5, 5

Yitzhaki, S. (1974): "A note on income tax evasion: A theoretical analysis," Journal of Public Economics, 3, 201-202. 1, 2 


\section{A Proofs of Propositions}

\section{A.1 Proposition 1}

The first order condition of the utility maximization problem are

$$
\begin{gathered}
\frac{\partial E U_{i}}{\partial F_{i t}}=0 \Longleftrightarrow \\
p u_{1}\left(\underline{I}_{i t}\right) I_{i t} \theta \tau-(1-p) u_{1}\left(\bar{I}_{i t}\right) I_{i t} \tau+\gamma_{1} s_{1}\left(F_{i t}, F_{i t-1}\right)+\gamma_{2} g_{1}\left(F_{i t}, F_{i t-1}, \Omega_{t-1}\right)=0
\end{gathered}
$$

where $u_{1}=\partial u(.) / \partial I_{i t}$ is the derivative of $u($.$) with respect to net income, and \underline{I}_{i t}$ and $\bar{I}_{i t}$ are individual $i$ 's net income when she is audited and when she is not audited, respectively. Namely $\underline{I}_{i t}=$ $I_{i t}\left(1-\tau F_{i t}-(\theta+1) \tau\left(1-F_{i t}\right)\right)$ and $\bar{I}_{i t}=I_{i t}\left(1-\tau F_{i t}\right) . s_{1}()=.\partial s(.) / \partial F_{i t}$ and $g_{1}()=.\partial g(.) / \partial F_{i t}$ are the derivatives of $s($.$) and g($.$) , respectively, with respect to individual i$ 's share of reported income, $F_{i t}$.

A risk averse agent underreports (i.e. the solution is in the interior) if, at $D_{i t}=I_{i t}=\bar{I}_{i t}=\underline{I}_{i t}$,

$$
\begin{gathered}
\left.\frac{\partial E U_{i}}{\partial F_{i t}}\right|_{F_{i t}=1}<0 \Longleftrightarrow \\
p u_{1}\left(I_{i t}\right) I_{i t} \theta \tau-(1-p) u_{1}\left(I_{i t}\right) I_{i t} \tau+\gamma_{1} s_{1}\left(1, F_{i t-1}\right)+\gamma_{2} g_{1}\left(1, F_{i t-1}, \Omega_{t-1}\right)<0 \\
1-(1+\theta) p-\gamma_{1} \frac{s_{1}\left(1, F_{i t-1}\right)}{u_{1}\left(I_{i t}\right) I_{i t} \tau}-\gamma_{2} \frac{g_{1}\left(1, F_{i t-1}, \Omega_{t-1}\right)}{u_{1}\left(I_{i t}\right) I_{i t} \tau}>0
\end{gathered}
$$

i.e. when the expected return from evading taxes, $1-(1+\theta) p$, adjusted to take into account the marginal private consistency cost of tax evasion, $\gamma_{1} s_{1}\left(1, F_{i t-1}\right) / u_{1}\left(I_{i t}\right) I_{i t} \tau$, and the marginal social cost of tax evasion, $\gamma_{2} g_{1}\left(1, F_{i t-1}, \Omega_{t-1}\right) / u_{1}\left(I_{i t}\right) I_{i t} \tau$, is strictly positive.

\section{A.2 Proposition 2}

A risk-averse individual that complied in $t-1$ underreports in $t$ if

$$
1-(1+\theta) p-\gamma_{1} \frac{s_{1}(1,1)}{u_{1}\left(I_{i t}\right) I_{i t} \tau}-\gamma_{2} \frac{g_{1}\left(1,1, \Omega_{t-1}\right)}{u_{1}\left(I_{i t}\right) I_{i t} \tau}>0
$$

If $s$ is supermodular in $\left(F_{i t}, F_{i t-1}\right)$ we have that in particular 31

$$
s(1,1)-s\left(1, F_{i t-1}\right) \geq s\left(F_{i t}, 1\right)-s\left(F_{i t}, F_{i t-1}\right)
$$

which, given the assumption of smoothness of the function $s$ can be rewritten as

$$
\lim _{F_{i t} \rightarrow 1} \frac{s(1,1)-s\left(F_{i t}, 1\right)}{1-F_{i t}} \geq \lim _{F_{i t} \rightarrow 1} \frac{s\left(1, F_{i t-1}\right)-s\left(F_{i t}, F_{i t-1}\right)}{1-F_{i t}} \Longleftrightarrow s_{1}(1,1) \geq s_{1}\left(1, F_{i t-1}\right) .
$$

Comparing the conditions for underreporting (9) and (8) we have that it is harder to sustain condition (9). This means that if $s(\cdot)$ is supermodular, the condition for underreporting is less likely to be met if we observe compliance in $t-1$ than if we observe underreporting in $t-1$. This effect is reinforced if $g(\cdot)$

\footnotetext{
${ }^{31}$ For functions on $R^{2}$, increasing differences is equivalent to supermodularity Amir (2005).
} 
is supermodular in $\left(F_{i t}, F_{i t-1}\right)$, which can be seen by applying an equivalent reasoning to the one that we applied to $s(\cdot)$.

\section{A.3 Proposition 3}

In Proposition 3 we study how information, either official or unofficial, affects the degree of persistence in income reporting behavior.

Before showing the proof we summarize its intuition. From the first order condition of the utility maximization problem we know that an agent underreports if the expected return from the action is positive. The expected return has three components: (i) the net effect of the tax savings, in case the agent is not audited, and the fine, in case the agent is audited; (ii) the marginal private consistency cost - which occurs when the agent changes behavior with respect to the previous period, and changes are harmful, i.e. the $s\left(F_{i t}, F_{i t-1}\right)$ function is supermodular; and (iii) the marginal social cost of tax evasion, which is similar to (ii) but can be affected by information on the behavior of a subset of the population. Information affects the persistence of the agent's behavior only through (iii), by affecting the degree of supermodularity of the $g\left(F_{i t}, F_{i t-1}, \Omega_{t-1}\right)$ function with respect to $\left(F_{i t}, F_{i t-1}\right)$. Now we turn to the proof.

From the the first order condition of the utility maximization problem, an agent underreports if

$$
p u_{1}\left(I_{i t}\right) I_{i t} \theta \tau-(1-p) u_{1}\left(I_{i t}\right) I_{i t} \tau+\gamma_{1} s_{1}\left(1, F_{i t-1}\right)+\gamma_{2} g_{1}\left(1, F_{i t-1}, \Omega_{t-1}\right)<0 .
$$

The agent is more likely to underreport in $t$ if she had underreported in $t-1$ the higher the combined supermodularity of $s\left(F_{i t}, F_{i t-1}\right)$ and $g\left(F_{i t}, F_{i t-1}, \Omega_{t-1}\right)$ with respect to $\left(F_{i t}, F_{i t-1}\right)$, i.e.

$$
\widetilde{\gamma}_{1} s_{12}\left(1, F_{i t-1}\right)+\widetilde{\gamma}_{2} g_{12}\left(1, F_{i t-1}, \Omega_{t-1}\right)>0
$$

This condition is more likely to be met if $\Omega_{t-1}$ "strengthens" the supermodularity of $g($.$) , i.e. if$

$$
\frac{\partial g_{12}\left(1, F_{i t-1}, \Omega_{t-1}\right)}{\partial \Omega_{t-1}}>0
$$

Note that the sign of the above inequality may depend on $F_{i t-1}$, i.e. on the behavior of the agent in the previous period.

\section{B Variables Definitions, Additional Descriptive Statistics, and Esti- mates}

\section{B.1 Variable Definitions}

Some concepts are recurring in the explanation of a majority of the tables and figures. We define them here, in alphabetical order, in detail.

All complied (i,t). A dummy variable equal to one if the messages that subject $i$ in period $t$ receives from her peers are all declarations of compliance, and zero otherwise.

All evaded $(\mathbf{i}, \mathbf{t})$. A dummy variable equal to one if the messages that subject $i$ in period $t$ receives from 
her peers are all declarations of evasion, and zero otherwise.

Audited (i,t-1). A dummy variable equal to one when the subject was audited in the previous period and zero otherwise.

Audited (i,t-2). A dummy variable equal to one when the subject was audited two periods before and zero otherwise.

Average evasion intensity $(\mathbf{i}, \mathbf{t})$. The average evasion intensity in $t-1$, communicated to subjects exposed to Treatment $\mathrm{A}$ in $t$.

Control (i,t). A dummy variable equal to one if subject $i$ receives neither treatment A nor treatment $\mathrm{B}$ in period $t$.

Earnings (i,t-1): The net income (after taxes and fines, in thousands of euros) earned by subject $i$ at the end of the previous round.

Evade (i,t). A dummy variable equal to one if the subject declared less than her income, and zero otherwise. In order to take into account potential rounding and unintentional income misreporting errors we codified the dummy variable to be equal to one only when the percentage of unreported income is greater than 1 percent.

Evasion intensity $(\mathbf{i}, \mathbf{t})$. A continuous variable equal to the ratio between declared income and income. Income $(\mathbf{i}, \mathbf{t})$. A subject's current gross income (before taxes and fines, in thousands of euros) received. Male. A dummy variable equal to one if the subject is male, and zero otherwise.

Over 24. A dummy variable equal to one if the subject is more than 24 years old, and zero otherwise. Periods (i,t). The number of periods since the beginning of the session.

Threshold (i,t). A dummy variable equal to one when the current income is 100 euros above the threshold of the assigned tax rate-i.e. either between 1,001 and 1,100 euros, or between 2,001 and 2,100 euros, or between 3,501 and 3,600 euros-and zero otherwise.

Tot. Earnings $(\mathbf{i}, \mathbf{t}-1)$. A subject's total net income, up to the income earned at the end of the previous round, cumulated from the beginning of the session.

Treatment A (i,t). A dummy variable equal to one if subject $i$ receives treatment A in period $t$.

Treatment B $(\mathbf{i}, \mathbf{t})$. A dummy variable equal to one if subject $i$ receives treatment B in period $t$.

Unemployed. A dummy variable equal to one if subject $i$ is unemployed, and zero otherwise.

\section{B.2 Additional Descriptive Statistics}

Table B.1 reports the mean and standard deviation of the main variables used in the analysis, for each treatment and control groups. Figure B.1 shows the distribution of the share of unreported income in the two treament groups and in the control group. Figure B.2 shows the distribution of the total earnings (in real world euros) at the end of the session in the two treament groups and in the control group. 
Table B.1: Summary statistics for all variables, by type of session

\begin{tabular}{|c|c|c|c|c|c|c|}
\hline \multirow{2}{*}{ Variable } & \multicolumn{2}{|c|}{ Control } & \multicolumn{2}{|c|}{ Treatment A } & \multicolumn{2}{|c|}{ Treatment B } \\
\hline & Mean & (Std. dev.) & Mean & (Std. dev.) & Mean & (Std. dev.) \\
\hline Evade $(0 / 1)$ & 0.281 & $(0.450)$ & 0.455 & $(0.498)$ & 0.462 & $(0.499)$ \\
\hline Unreported income (\%) & 5.689 & $(13.875)$ & 13.276 & $(22.305)$ & 15.602 & $(25.331)$ \\
\hline Audited $(0 / 1)$ & 0.232 & $(0.423)$ & 0.277 & $(0.448)$ & 0.245 & $(0.431)$ \\
\hline Earnings & 1.667 & $(0.812)$ & 1.579 & $(1.346)$ & 1.600 & $(1.336)$ \\
\hline Total earnings & 10.99 & $(6.195)$ & 11.345 & $(6.100)$ & 9.894 & $(6.479)$ \\
\hline Income & 2.544 & $(1.169)$ & 2.563 & $(1.163)$ & 2.515 & $(1.146)$ \\
\hline Threshold $(0 / 1)$ & 0.075 & $(0.265)$ & 0.063 & $(0.243)$ & 0.077 & $(0.267)$ \\
\hline Over $24(0 / 1)$ & 0.188 & $(0.391)$ & 0.379 & $(0.486)$ & 0.308 & $(0.462)$ \\
\hline Unemployed $(0 / 1)$ & 0.812 & $(0.391)$ & 0.621 & $(0.486)$ & 0.673 & $(0.469)$ \\
\hline Male $(0 / 1)$ & 0.375 & $(0.485)$ & 0.534 & $(0.499)$ & 0.519 & $(0.500)$ \\
\hline Aver. evasion intensity in t-1 (\%) & & & 13.179 & $(5.933)$ & & \\
\hline All evaded in $t-1(0 / 1)$ & & & & & 0.050 & $(0.217)$ \\
\hline All complied in t-1 $(0 / 1)$ & & & & & 0.045 & $(0.207)$ \\
\hline Observations & & 384 & & 638 & & 624 \\
\hline
\end{tabular}

Notes: The table shows the average and standard deviation for all the variables and samples considered in the empirical analysis of Section 5 by type of session. The definition of all variables can be found in Appendix B

Figure B.1: Distribution of the Share of Unreported Income, Treatments and Control Groups

(a) Control

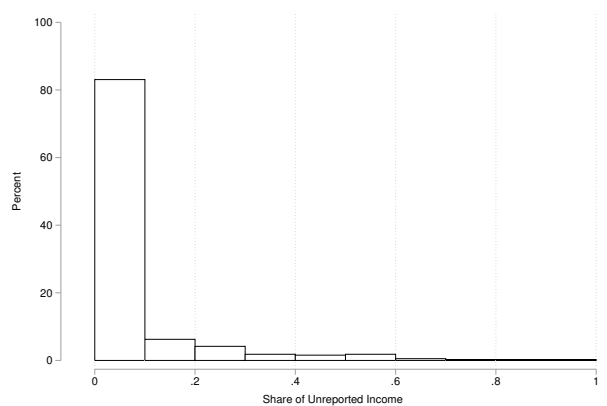

(b) Official Information Treatment

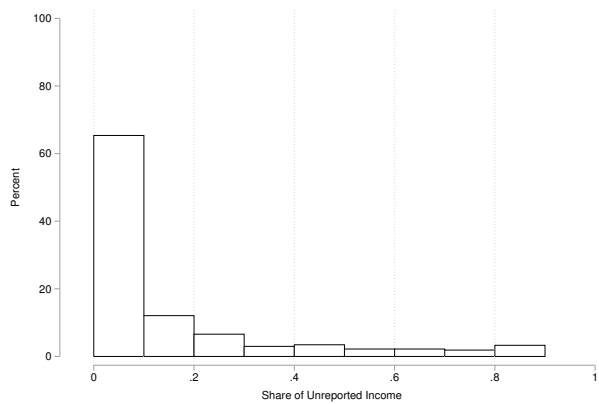

(c) Unofficial Information Treatment

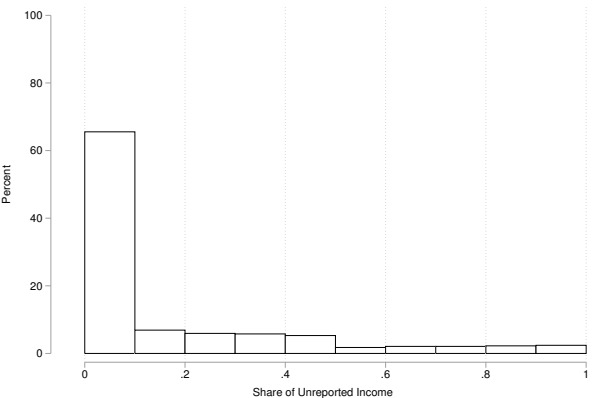

Figure B.2: Distribution of Total Earnings at the End of Each Session, Treatments and Control Groups

(a) Control

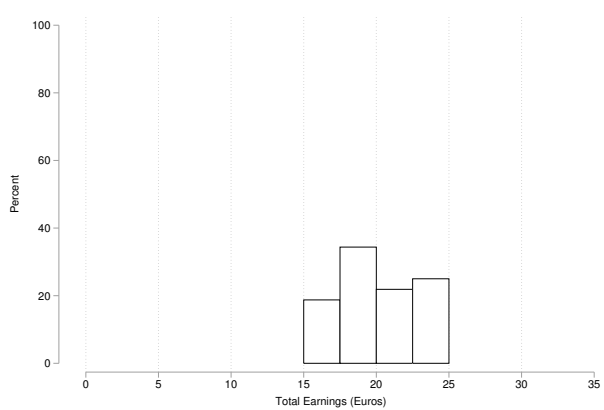

(b) Official Information Treatment



(c) Unofficial Information Treatment

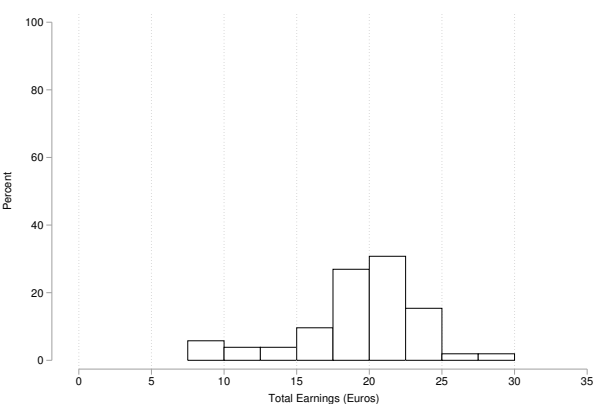




\section{B.3 Estimates}

\section{B.3.1 Baseline, Robustness, and Extensions Results}

While in the main text we report and discuss the average marginal effects of the main covariates of interest, we report here, for completeness, the simple estimates of the specifications and covariates employed in the analysis.

Table B.2 reports the estimates associated to the baseline results of Section 6.1 and 6.2. Table B.3. and B.4 report the estimates associated to the linear model, and to the Bayesian exercise, respectively, of Section 6.1.1. Finally, Table B.5 reports the estimates of the nonlinear model of Section 6.1.1 where the dependent variable is evasion intensity. 
Table B.2: Estimates of the effect of official and unofficial information on the probability of evasion

\begin{tabular}{|c|c|c|c|c|}
\hline \multirow{2}{*}{ Evaded in $t-1(0 / 1)$} & 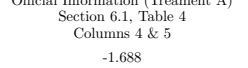 & 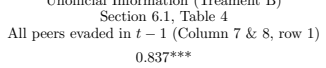 & 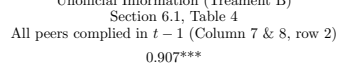 &  \\
\hline & $(1.355)$ & $(0.152)$ & $(0.151)$ & $(0.177)$ \\
\hline \multirow[t]{2}{*}{ Average evasion intensity in $t-1\left(A V E_{t}\right)$} & $-14.855^{* *}$ & & & \\
\hline & $(7.337)$ & & & \\
\hline \multirow[t]{2}{*}{ Evaded in $t-1 \times A V E_{t}$} & $14.254^{* *}$ & & & \\
\hline & (7.069) & & & \\
\hline \multirow[t]{2}{*}{$A V E_{t}>$ own evasion (Gap below median) (0/1) } & -2.077 & & & \\
\hline & (1.394) & & & \\
\hline \multirow[t]{2}{*}{$A V E_{t}>$ own evasion (Gap above median) (0/1) } & $-2.226^{*}$ & & & \\
\hline & $(1.323)$ & & & \\
\hline \multirow[t]{2}{*}{ Evaded in $t-1 \times A V E_{t}>$ own evasion (Gap below median) } & 1.056 & & & \\
\hline & $(1.391)$ & & & \\
\hline \multirow[t]{2}{*}{$A V E_{t} \times A V E_{t}>$ own evasion (Gap below median) } & 4.192 & & & \\
\hline & (9.194) & & & \\
\hline \multirow[t]{2}{*}{$A V E_{t} \times A V E_{t}>$ own evasion (Gap above median) } & $11.961^{*}$ & & & \\
\hline & $(7.022)$ & & & \\
\hline \multirow[t]{2}{*}{ Evaded in $t-1 \times A V E_{t}>$ own evasion (Gap below median) $\times A V E_{t}$} & 3.029 & & & \\
\hline & $(9.556)$ & & & \\
\hline \multirow[t]{2}{*}{ All peers evaded in $t-1$} & & $1.171^{* *}$ & & \\
\hline & & $(0.482)$ & & \\
\hline \multirow[t]{2}{*}{ Evaded in $t-1 \times$ All peers evaded in $t-1$} & & $-0.659 * *$ & & \\
\hline & & $(0.526)$ & & \\
\hline \multirow[t]{2}{*}{ All peers complied in $t-1$} & & & 0.162 & \\
\hline & & & $(0.301)$ & \\
\hline Evaded in $t-1 \times$ All peers complied in $t-1$ & & & $-0.599^{*}$ & \\
\hline & & & $(0.363)$ & \\
\hline Evaded in $t-2$ & $0.569^{* * *}$ & $0.687^{* * *}$ & $0.672^{* * *}$ & $0.980^{* * * *}$ \\
\hline & $(0.1454)$ & $(0.158)$ & $(0.159)$ & $(0.145)$ \\
\hline Evaded in $t-1 \times$ Evaded in $t-2$ & & & & $-0.618^{* * *}$ \\
\hline & & & & $(0.202)$ \\
\hline Audited in $t-1$ & 0.030 & $0.503^{* * *}$ & $0.479^{* * *}$ & $0.254^{* *}$ \\
\hline & $(0.140)$ & $(0.144)$ & $(0.146)$ & $(0.124)$ \\
\hline Evaded in $t-1 \times$ Audited in $t-1$ & & & & -0.191 \\
\hline & & & & $(0.201)$ \\
\hline Audited in $t-2$ & 0.122 & -0.048 & -0.063 & 0.020 \\
\hline & $(0.130)$ & $(0.153)$ & $(0.162)$ & $(0.104)$ \\
\hline Evaded in $t-2 \times$ Audited in $t-2$ & & & & -0.076 \\
\hline & & & & $(0.166)$ \\
\hline Earnings in $t-1$ & 0.005 & -0.008 & -0.014 & -0.032 \\
\hline & $(0.053)$ & $(0.062)$ & $(0.057)$ & $(0.039)$ \\
\hline Total Earnings in $t-1$ & 0.000 & 0.021 & 0.014 & 0.000 \\
\hline & $(0.015)$ & $(0.016)$ & $(0.017)$ & $(0.012)$ \\
\hline Income in $t$ & 0.074 & 0.064 & 0.075 & 0.053 \\
\hline & $(0.060)$ & $(0.057)$ & $(0.057)$ & $(0.037)$ \\
\hline Male $(0 / 1)$ & 0.130 & $0.251^{*}$ & $0.279^{* *}$ & $0.226^{*}$ \\
\hline & $(0.136)$ & $(0.138)$ & $(0.136)$ & $(0.132)$ \\
\hline Evaded in $t-1 \times$ Male $(0 / 1)$ & & & & -0.334 \\
\hline & & & & $(0.206)$ \\
\hline Threshold $(0 / 1)$ & $0.525^{*}$ & $0.511^{*}$ & $0.494^{*}$ & 0.405 \\
\hline & $(0.286)$ & $(0.276)$ & $(0.268)$ & $(0.253)$ \\
\hline Evaded in $t-1 \times$ Threshold $(0 / 1)$ & & & & $-0.619^{* *}$ \\
\hline & & & & $(0.299)$ \\
\hline Evaded in $t-1 \times$ Male $(0 / 1) \times$ Threshold $(0 / 1)$ & & & & 0.514 \\
\hline & & & & $(0.631)$ \\
\hline Treatment B $(0 / 1)$ & & & & 0.039 \\
\hline & & & & $(0.083)$ \\
\hline Control Group (0/1) & & & & $-0.268^{* *}$ \\
\hline & & & & $(0.115)$ \\
\hline Period & -0.016 & $-0.050^{*}$ & -0.039 & -0.011 \\
\hline & $(0.028)$ & $(0.027)$ & $(0.028)$ & $(0.019)$ \\
\hline Over $24(0 / 1)$ & $-0.251^{*}$ & -0.089 & -0.117 & -0.057 \\
\hline & $(0.152)$ & $(0.168)$ & $(0.162)$ & $(0.099)$ \\
\hline Unemployed (0/1) & -0.235 & -0.093 & -0.082 & -0.037 \\
\hline & $(0.154)$ & $(0.176)$ & $(0.171)$ & $(0.104)$ \\
\hline Av. Session Income & 0.091 & -0.305 & -0.205 & \\
\hline & $(0.239)$ & $(0.213)$ & $(0.208)$ & \\
\hline Constant & 1.685 & -0.242 & -0.510 & $-1.187^{* * * *}$ \\
\hline & $(1.492)$ & $(0.537)$ & $(0.530)$ & $(0.207)$ \\
\hline Observations & 580 & 520 & 520 & 1468 \\
\hline
\end{tabular}

Notes: Standard errors robust to serial correlation in parentheses, 43 statistically significant at the $1 \%(* * *), 5 \%(* *), 10 \%(*)$ level. 
Table B.3: Estimates of the effect of official and unofficial information on the probability of evasion, linear model DD

\begin{tabular}{|c|c|c|c|}
\hline & Columins \& 2 & All peers evaded in $t=1$ Colum! \& \& 4 , row 1$)$ & All peers complied in $\frac{0.1 .1}{-1}$ Columm $3 \& 4$, row 2$)$ \\
\hline \multirow[t]{2}{*}{ Evaded in $t-1(0 / 1)$} & $0.146^{* * *}$ & $0.177^{* * *}$ & $0.179^{* * *}$ \\
\hline & $(0.051)$ & $(0.035)$ & $(0.034)$ \\
\hline \multirow[t]{2}{*}{ Average evasion intensity in $t-1\left(A V E_{t}\right)$} & -0.727 & & \\
\hline & $(0.798)$ & & \\
\hline \multirow[t]{2}{*}{ Evaded in $t-1 \times A V E_{t}$} & $4.185^{* *}$ & & \\
\hline & $(2.111)$ & & \\
\hline \multirow[t]{2}{*}{$A V E_{t}<$ own evasion $(0 / 1)$} & $0.191^{*}$ & & \\
\hline & $(0.103)$ & & \\
\hline \multirow[t]{2}{*}{$A V E_{t}>$ own evasion (Gap below median) $(0 / 1)$} & $0.273^{* *}$ & & \\
\hline & $(0.138)$ & & \\
\hline \multirow[t]{2}{*}{$A V E_{t}>$ own evasion (Gap above median) $(0 / 1)$} & 0.227 & & \\
\hline & $(0.141)$ & & \\
\hline \multirow[t]{2}{*}{ Evaded in $t-1 \times A V E_{t}>$ own evasion (Gap below median) } & $-0.391^{*}$ & & \\
\hline & $(0.210)$ & & \\
\hline \multirow[t]{2}{*}{ Evaded in $t-1 \times A V E_{t}>$ own evasion (Gap above median) } & -0.726 & & \\
\hline & $(0.454)$ & & \\
\hline \multirow[t]{2}{*}{$A V E_{t} \times A V E_{t}<$ own evasion } & $-3.680^{*}$ & & \\
\hline & $(2.050)$ & & \\
\hline \multirow[t]{2}{*}{$A V E_{t} \times A V E_{t}>$ own evasion (Gap below median) } & -2.305 & & \\
\hline & $(1.953)$ & & \\
\hline \multirow[t]{2}{*}{ Evaded in $t-1 \times A V E_{t}>$ own evasion (Gap below median) $\times A V E_{t}$} & 0.914 & & \\
\hline & $(2.903)$ & & \\
\hline \multirow[t]{2}{*}{ All peers evaded in $t-1$} & & $0.399^{* *}$ & \\
\hline & & $(0.144)$ & \\
\hline \multirow[t]{2}{*}{ Evaded in $t-1 \times$ All peers evaded in $t-1$} & & -0.209 & \\
\hline & & $(0.170)$ & \\
\hline \multirow[t]{2}{*}{ All peers complied in $t-1$} & & & 0.010 \\
\hline & & & $(0.097)$ \\
\hline \multirow[t]{2}{*}{ Evaded in $t-1 \times$ All peers complied in $t-1$} & & & -0.138 \\
\hline & & & $(0.268)$ \\
\hline \multirow[t]{2}{*}{ Evaded in $t-2$} & $0.273^{* * *}$ & $0.294^{* * *}$ & $0.296^{* * *}$ \\
\hline & $(0.034)$ & $(0.035)$ & $(0.035)$ \\
\hline \multirow[t]{2}{*}{ Audited in $t-1$} & -0.007 & $0.085^{* *}$ & $0.082^{* *}$ \\
\hline & $(0.035)$ & $(0.037)$ & $(0.037)$ \\
\hline \multirow{2}{*}{ Audited in $t-2$} & 0.010 & -0.020 & -0.022 \\
\hline & $(0.034)$ & $(0.035)$ & $(0.035)$ \\
\hline Earnings in $t-1$ & 0.002 & -0.014 & -0.014 \\
\hline & $(0.016)$ & $(0.016)$ & $(0.015)$ \\
\hline Total Earnings in $t-1$ & -0.006 & 0.002 & 0.001 \\
\hline & $(0.006)$ & $(0.006)$ & $(0.006)$ \\
\hline Income in $t$ & 0.020 & 0.015 & 0.016 \\
\hline & $(0.013)$ & $(0.013)$ & $(0.013)$ \\
\hline Male $(0 / 1)$ & 0.002 & 0.035 & 0.043 \\
\hline & $(0.030)$ & $(0.031)$ & $(0.030)$ \\
\hline Threshold (0/1) & $0.111^{*}$ & $0.114^{*}$ & $0.111^{*}$ \\
\hline & $(0.062)$ & $(0.060)$ & $(0.060)$ \\
\hline Period & 0.007 & -0.005 & -0.001 \\
\hline & $(0.011)$ & $(0.011)$ & $(0.011)$ \\
\hline Over $24(0 / 1)$ & -0.019 & 0.019 & 0.012 \\
\hline & $(0.041)$ & $(0.042)$ & $(0.042)$ \\
\hline Unemployed (0/1) & -0.011 & 0.020 & 0.021 \\
\hline & $(0.042)$ & $(0.040)$ & $(0.039)$ \\
\hline Av. Session Income & 0.035 & -0.072 & -0.044 \\
\hline & $(0.065)$ & $(0.064)$ & $(0.062)$ \\
\hline Constant & 0.020 & -0.242 & $0.300^{*}$ \\
\hline & $(0.183)$ & $(0.537)$ & $(0.168)$ \\
\hline Observations & 948 & 888 & 888 \\
\hline
\end{tabular}

Notes: Standard errors robust to serial correlation in parentheses, statistically significant at the $1 \%(* * *), 5 \%(* *), 10 \%(*)$ level. 
Table B.4: Estimates of the effect of official and unofficial information on the probability of evasion, Bayesian interpretation

\begin{tabular}{|c|c|c|}
\hline & $\begin{array}{c}\text { Official Information (Treament A) (Bayesian) } \\
\text { Section 6.1.1, Table } 6 \text { ( } \\
\text { Columns } 2 \text { \& } 3\end{array}$ & $\begin{array}{c}\text { Unofficial Information (Treament B) (Bayesian) } \\
\text { Section } 6.1 .1, \text { Table } 6 \\
\text { Column } 5 \text { \& } 6\end{array}$ \\
\hline \multirow[t]{2}{*}{ Evaded in $t-1(0 / 1)$} & 1.088 & 0.370 \\
\hline & $(1.389)$ & $(0.595)$ \\
\hline \multirow[t]{2}{*}{ Posterior mean share of evaders $\left(\tilde{\mu}_{i t}\right)$} & 1.454 & -0.559 \\
\hline & $(1.600)$ & $(0.748)$ \\
\hline \multirow[t]{2}{*}{ Evaded in $t-1 \times \tilde{\mu}_{i t}$} & 0.051 & 1.378 \\
\hline & $(1.946)$ & $(1.338)$ \\
\hline \multirow[t]{2}{*}{ Posterior s.d. share of evaders $\left(\tilde{\sigma}_{i t}^{-1}\right)$} & -0.005 & -0.002 \\
\hline & $(0.089)$ & $(0.043)$ \\
\hline \multirow[t]{2}{*}{ Evaded in $t-1 \times \tilde{\sigma}_{i t}^{-1}$} & -0.030 & 0.013 \\
\hline & $(0.073)$ & $(0.074)$ \\
\hline \multirow[t]{2}{*}{$\tilde{\mu}_{i t} \times \tilde{\sigma}_{i t}^{-1}$} & -0.012 & 0.034 \\
\hline & $(0.096)$ & $(0.106)$ \\
\hline \multirow[t]{2}{*}{ Evaded in $t-1 \times \tilde{\mu}_{i t} \times \tilde{\sigma}_{i t}^{-1}$} & 0.027 & -0.025 \\
\hline & $(0.085)$ & $(0.175)$ \\
\hline \multirow[t]{2}{*}{ Evaded in $t-2$} & $0.573^{* * *}$ & $0.654^{* * *}$ \\
\hline & $(0.162)$ & $(0.163)$ \\
\hline \multirow{2}{*}{ Audited in $t-1$} & 0.051 & $0.482^{* * *}$ \\
\hline & $(0.130)$ & $(0.144)$ \\
\hline \multirow{2}{*}{ Audited in $t-2$} & 0.127 & -0.066 \\
\hline & $(0.131)$ & $(0.160)$ \\
\hline \multirow[t]{2}{*}{ Earnings in $t-1$} & 0.011 & -0.015 \\
\hline & $(0.056)$ & $(0.065)$ \\
\hline \multirow[t]{2}{*}{ Total Earnings in $t-1$} & -0.000 & 0.025 \\
\hline & $(0.017)$ & $(0.018)$ \\
\hline \multirow[t]{2}{*}{ Income in $t$} & 0.061 & 0.068 \\
\hline & $(0.062)$ & $(0.055)$ \\
\hline \multirow[t]{2}{*}{ Male $(0 / 1)$} & 0.196 & 0.196 \\
\hline & $(0.150)$ & $(0.150)$ \\
\hline \multirow[t]{2}{*}{ Threshold $(0 / 1)$} & 0.439 & $0.482^{*}$ \\
\hline & $(0.236)$ & $(0.258)$ \\
\hline \multirow[t]{2}{*}{ Period } & 0.011 & -0.064 \\
\hline & $(0.056)$ & $(0.040)$ \\
\hline \multirow[t]{2}{*}{ Over $24(0 / 1)$} & $-0.316^{*}$ & -0.052 \\
\hline & $(0.162)$ & $(0.171)$ \\
\hline \multirow[t]{2}{*}{ Unemployed $(0 / 1)$} & $-0.302^{*}$ & -0.058 \\
\hline & $(0.165)$ & $(0.175)$ \\
\hline \multirow[t]{2}{*}{ Av. Session Income } & 0.125 & -0.312 \\
\hline & $(0.228)$ & $(0.264)$ \\
\hline \multirow[t]{2}{*}{ Constant } & -1.958 & -0.009 \\
\hline & $(1.416)$ & $(0.704)$ \\
\hline Observations & 580 & 520 \\
\hline
\end{tabular}

Notes: Standard errors robust to serial correlation in parentheses, statistically significant at the $1 \%(* * *), 5 \%(* *), 10 \%(*)$ level. 
Table B.5: Estimates of the effect of official and unofficial information on evasion intensity

\begin{tabular}{|c|c|c|c|}
\hline \multirow[t]{2}{*}{ Evaded in $t-1(0 / 1)$} & $\begin{array}{l}\text { Columis \& \& } 5 \\
-0.277^{* *}\end{array}$ & $\begin{array}{c}\text { All peers evaded in } t=1 . \text { Colum } \\
0.042^{*}\end{array}$ & $\begin{array}{c}\left.\text { All peers complied in } \frac{1.1 .1}{t-1} \text { Colunn } 7 \& 8 \text {, row } 2\right) \\
0.045^{* *}\end{array}$ \\
\hline & $(0.118)$ & $(0.022)$ & $(0.023)$ \\
\hline \multirow[t]{2}{*}{ Average evasion intensity in $t-1\left(A V E_{t}\right)$} & $-1.895^{* * *}$ & & \\
\hline & $(0.735)$ & & \\
\hline \multirow[t]{2}{*}{ Evaded in $t-1 \times A V E_{t}$} & $1.589 * *$ & & \\
\hline & $(0.622)$ & & \\
\hline \multirow[t]{2}{*}{$A V E_{t}>$ own evasion (Gap below median) $(0 / 1)$} & -0.125 & & \\
\hline & $(0.150)$ & & \\
\hline \multirow[t]{2}{*}{$A V E_{t}>$ own evasion (Gap above median) $(0 / 1)$} & $-0.261^{* *}$ & & \\
\hline & $(0.122)$ & & \\
\hline \multirow[t]{2}{*}{ Evaded in $t-1 \times A V E_{t}>$ own evasion (Gap below median) } & 0.080 & & \\
\hline & $(0.139)$ & & \\
\hline \multirow{2}{*}{$A V E_{t} \times A V E_{t}>$ own evasion (Gap below median) } & -0.168 & & \\
\hline & $(1.183)$ & & \\
\hline \multirow[t]{2}{*}{$A V E_{t} \times A V E_{t}>$ own evasion (Gap above median) } & $1.530^{* *}$ & & \\
\hline & $(0.681)$ & & \\
\hline \multirow[t]{2}{*}{ Evaded in $t-1 \times A V E_{t}>$ own evasion (Gap below median) $\times A V E_{t}$} & 0.665 & & \\
\hline & $(1.068)$ & & \\
\hline \multirow[t]{2}{*}{ All peers evaded in $t-1$} & & 0.099 & \\
\hline & & $(0.075)$ & \\
\hline \multirow[t]{2}{*}{ Evaded in $t-1 \times$ All peers evaded in $t-1$} & & -0.009 & \\
\hline & & $(0.068)$ & \\
\hline \multirow[t]{2}{*}{ All peers complied in $t-1$} & & & -0.008 \\
\hline & & & $(0.035)$ \\
\hline \multirow{2}{*}{ Evaded in $t-1 \times$ All peers complied in $t-1$} & & & -0.011 \\
\hline & & & $(0.050)$ \\
\hline \multirow[t]{2}{*}{ Share of unreported income in $t-1$} & $0.420^{* * *}$ & $0.243^{* * *}$ & $0.261^{* * *}$ \\
\hline & $(0.101)$ & $(0.033)$ & $(0.033)$ \\
\hline \multirow[t]{2}{*}{ Share of unreported income in $t-2$} & $0.163^{* *}$ & $0.241^{* * *}$ & $0.237^{* * *}$ \\
\hline & $(0.072)$ & $(0.051)$ & $(0.051)$ \\
\hline \multirow[t]{2}{*}{ Audited in $t-1$} & 0.023 & $0.078^{* *}$ & $0.077^{* *}$ \\
\hline & $(0.019)$ & $(0.032)$ & $(0.032)$ \\
\hline \multirow[t]{2}{*}{ Audited in $t-2$} & 0.000 & -0.042 & -0.046 \\
\hline & $(0.018)$ & $(0.027)$ & $(0.029)$ \\
\hline \multirow[t]{2}{*}{ Earnings in $t-1$} & -0.009 & $-0.023^{* *}$ & $-0.023^{* *}$ \\
\hline & $(0.014)$ & $(0.011)$ & $(0.010)$ \\
\hline \multirow[t]{2}{*}{ Total Earnings in $t-1$} & 0.000 & 0.002 & 0.000 \\
\hline & $(0.003)$ & $(0.002)$ & $(0.002)$ \\
\hline \multirow[t]{2}{*}{ Income in $t$} & 0.019 & $0.031^{* *}$ & $0.033^{* * *}$ \\
\hline & $(0.010)$ & $(0.012)$ & $(0.012)$ \\
\hline Male $(0 / 1)$ & 0.013 & $0.049^{* *}$ & $0.054^{* *}$ \\
\hline & $(0.017)$ & $(0.021)$ & $(0.022)$ \\
\hline Threshold $(0 / 1)$ & -0.007 & 0.005 & 0.003 \\
\hline & $(0.036)$ & $(0.040)$ & $(0.041)$ \\
\hline Period & -0.002 & -0.004 & -0.002 \\
\hline & $(0.005)$ & $(0.004)$ & $(0.004)$ \\
\hline Over $24(0 / 1)$ & -0.022 & 0.013 & 0.010 \\
\hline & $(0.019)$ & $(0.021)$ & $(0.023)$ \\
\hline Unemployed $(0 / 1)$ & -0.023 & 0.032 & 0.035 \\
\hline & $(0.020)$ & $(0.021)$ & $(0.023)$ \\
\hline Av. Session Income & -0.009 & -0.046 & -0.032 \\
\hline & $(0.040)$ & $(0.030)$ & $(0.034)$ \\
\hline Constant & $0.371^{* * *}$ & 0.091 & 0.053 \\
\hline & $(0.143)$ & $(0.071)$ & $(0.087)$ \\
\hline Observations & 580 & 520 & 520 \\
\hline
\end{tabular}

Notes: Standard errors robust to serial correlation in parentheses, statistically significant at the $1 \%(* * *), 5 \%(* *), 10 \%(*)$ level. 


\section{Experimental Design: Additional Information}

\section{C.1 Descriptions of Rounds}

Table C.1 summarizes the steps and actions characterizing each round of the control, official information treatment, and unofficial information treatment sessions.

Table C.1: Description of actions in each round, by session type

\begin{tabular}{|c|c|c|}
\hline $\begin{array}{c}\text { Control } \\
\text { (No information) }\end{array}$ & $\begin{array}{c}\text { Treatment A } \\
\text { (Official information) }\end{array}$ & $\begin{array}{c}\text { Treatment B } \\
\text { (Unofficial information) }\end{array}$ \\
\hline 1) Participants receive a & 1) Participants receive a & 1) Participants receive a \\
\hline level of income from a & level of income from a & level of income from a \\
\hline Uniform between 500 and & Uniform between 500 and & Uniform between 500 and \\
\hline 4,500 laboratory Euros & 4,500 laboratory Euros & 4,500 laboratory Euros \\
\hline $\begin{array}{l}\text { 2) Participants are informed } \\
\text { of the tax rate they are } \\
\text { subject to, based on the } \\
\text { assigned income }\end{array}$ & $\begin{array}{l}\text { 2) Participants are informed } \\
\text { of the tax rate they are } \\
\text { subject to, based on the } \\
\text { assigned income }\end{array}$ & $\begin{array}{l}\text { 2) Participants are informed } \\
\text { of the tax rate they are } \\
\text { subject to, based on the } \\
\text { assigned income }\end{array}$ \\
\hline & $\begin{array}{l}\text { 3) Participants are informed } \\
\text { about the average } \\
\text { percentage of unreported } \\
\text { income by all the subjects in } \\
\text { the previous round }\end{array}$ & $\begin{array}{l}\text { 3) Participants can send a } \\
\text { message about the } \\
\text { percentage of reported } \\
\text { income, in the previous } \\
\text { round, to the other three } \\
\text { members of their group of } \\
\text { "peers" }\end{array}$ \\
\hline & & $\begin{array}{l}\text { 4) Participants may receive } \\
\text { a message about the } \\
\text { percentage of reported } \\
\text { income, in the previous } \\
\text { round, by any of the three } \\
\text { other members of their } \\
\text { group of "peers" }\end{array}$ \\
\hline $\begin{array}{l}\text { 3) Participants declare their } \\
\text { income }\end{array}$ & $\begin{array}{l}\text { 4) Participants declare their } \\
\text { income }\end{array}$ & $\begin{array}{l}\text { 5) Participants declare their } \\
\text { income }\end{array}$ \\
\hline $\begin{array}{l}\text { 4) Participants are audited } \\
\text { with probability } p\end{array}$ & $\begin{array}{l}\text { 5) Participants are audited } \\
\text { with probability } p\end{array}$ & $\begin{array}{l}\text { 6) Participants are audited } \\
\text { with probability } p\end{array}$ \\
\hline $\begin{array}{l}\text { 5) Participants are informed } \\
\text { about their results, and go } \\
\text { to the next round }\end{array}$ & $\begin{array}{l}\text { 6) Participants are informed } \\
\text { about their results, and go } \\
\text { to the next round }\end{array}$ & $\begin{array}{l}\text { 7) Participants are informed } \\
\text { about their results, and go } \\
\text { to the next round }\end{array}$ \\
\hline 12 rounds & 12 rounds & 12 rounds \\
\hline 32 participants & 58 participants & 52 participants \\
\hline 384 observations & 696 observations & 624 observations \\
\hline
\end{tabular}




\section{C.2 Instructions}

The following is the set of instructions - translated from Portuguese to English — given to the subjects of the experiment.

1. This treatment consists of 12 rounds, i.e. 12 moments in which you will be asked to declare your income for taxation purposes.

2. In each round you will be assigned a level of income that varies between 500 and 4,500 experimental euros.

3. The probability of being audited is 25 percent in each round.

4. If you are audited and you declared less than your actual income you will be fined in the amount of seven times the unpaid taxes.

Example:

(a) If your income is 3,000 you are subject to a 30 percent tax rate.

(b) If you declare 2,000 you will pay $2,000 * 30 \%=600$.

(c) If you are audited you will be found to have evaded taxes since you declared 1,000 euro less than you should have.

(d) In this case, your fine is equal to $7^{*} 1,000 * 30 \%=2,100$ euros. Your final earnings are: 3,000$2,000 * 30 \%-7 * 1,000 * 30 \%=300$. If you declared correctly you will have 2,100 .

5. In the case of Treatment A:

At the beginning of each round, except for the first, you will be informed on the average share of unreported income by the participants in the previous period.

In the case of Treatment B:

Starting from the first round, you will have the possibility of communicating to three participants your declaration behavior in the previous round.

In the case of Control: No additional instructions.

6. At the end of each round, you will be informed if you were audited or not. At the end of the 12 rounds you will be informed on your total earning net of taxes and fines.

7. If, during the experiment, your earnings are negative you will have the option of either continuing the experiment but giving up the participation premium or terminating the experiment and receive just the participation premium.

8. At the end of each treatment you will have to wait for the next treatment to start.

9. The payment for participating in the experiment is a function of your performance during the experiment, specifically, you will receive 1 euro for every 4,000 experimental euros.

10. The first 3 rounds are for testing purposes, they are just meant for you to get used to the software and do not affect your earnings.

11. At the end of the experiment you will be asked to fill in a short questionnaire. 


\section{C.3 Tax brackets}

Table C.2 reports the tax rates associated with each level of income.

Table C.2: Income Progressive Tax Rates

\begin{tabular}{|ccccc|}
\hline$\tau$ & 0.12 & 0.25 & 0.30 & 0.40 \\
\hline$I$ & $500-1000$ & $1001-2000$ & $2001-3500$ & $3501-4500$ \\
\hline
\end{tabular}

